\title{
Direct Dissolution of Cellulose: Background, Means and Applications
}

\author{
Carina Olsson and Gunnar Westman
}

Additional information is available at the end of the chapter

http://dx.doi.org/10.5772/52144

\section{Introduction}

Being the main structural component in plants, cellulose is by far the most abundant organic polymer on earth. The highest quantity of cellulose is found in the secondary walls of higher plants, such as wood, were the polymer is incorporated in a matrix of lignin and shorter heteropolysaccharides such as hemicelluloses and pectins. Cellulose is also found in some fungi and algae, in the marine animal family of tunicates and as an extracellular product of some bacteria. In theory, cellulose is an inexhaustible resource and yields $1.5 \times 10^{12}$ tons of biomass every year. Despite the fact that cellulose is available in any plant, wood pulp provides the main part of cellulose used today, for example in board, paper and textile. Historically, cellulose has been used for as long as man has existed, first as fuel and shelter and later for clothing and writing material such as papyrus. Cotton was domesticated thousands of years ago and the soft fiber surrounding the cotton seed was used for making textiles in many parts of the world. Cotton is still the main source of cellulose for textile but the demand for wood based raw material is increasing due to the environmental drawbacks associated with cotton cultivation and processing, such as high water and pesticide usage. Both cotton and wood based cellulose can also be used as the basis for cellulose derivatives such as cellulose ethers and cellulose esters. These are widely used, for example in pharmaceuticals, food, construction materials and paint. When it comes to sustainable raw materials for future demands on fuel, chemicals and materials, both bulk and high performance, cellulose is definitely a resource of great importance and still today one that is underutilized.

Corpora non agunt nisi solute (substances do not react unless dissolved) is a statement with roots in ancient alchemy, and still has some validity today. Unlike many petroleum based polymers, cellulose will not melt but decompose at elevated temperatures. To get the cellulose in liquid form, it has to be dissolved or chemically modified. Homogeneous 
reaction as a route to add functionality to the reactive cellulose hydroxyl groups provides better control of total degree of substitution and better conditions to control not only the substitution pattern along the cellulose chain but potentially even the substitution pattern within each monomer since each part of the polymer is, at least in theory, equally exposed to reagents and solvent. Due to its chemical composition, cellulose is insoluble or only partly soluble in most common solvents. Although quite a few alternatives have proven useful over the years, the search for efficient and non-degrading solvents for cellulose is still ongoing and in the light of current trends within sustainability and exploration of alternatives for oil based products, this work is now more important than ever. Suitable solvents for cellulose are not only essential in homogeneous reactions, but are indispensable in the characterization of the polymer itself, and last but not least in the shaping of cellulose into e.g. textile fibers, films and membranes.

One of the most successful routes to dissolving and shaping of cellulose is via the viscose process. This technique involves conversion of cellulose to cellulose xanthogenate, by a reaction with carbon disulfide in sodium hydroxide first described by Charles Frederick Cross, Edward John Bevan, and Clayton Beadle [1]. The metastable cellulose xanthogenate is soluble in aqueous sodium hydroxide and the resulting viscous liquid is used as a spin dope. This means that the dissolved polymer is not actually cellulose but a cellulose derivative. The polymer is then precipitated in acid, for simultaneous neutralization and regeneration of the cellulose in a wet spinning step. Hence, the resulting regenerated fiber will be pure cellulose. This process is still today widely used to make viscose textile and cellophane. The viscose process yields high performance fibers with excellent properties for various applications, but it has some drawbacks. The sulfuric reagents, their byproducts and the heavy metals used in the regeneration baths are, despite a decrease in usage, still a problem from an environmental point of view. Both air and water streams must be adequately purified to meet today's regulations.

In an attempt to avoid some of the problems associated with the in some sense outdated viscose process, numerous alternatives have been developed. One method where all existing technology can be translated directly from the viscose process to new chemistry is the carbamate process, where urea is used to produce cellulose carbamate, a derivative soluble in aqueous sodium hydroxide that can be fed into the ordinary viscose line [2]. The process utilizes alkalized and pre-ripened pulp in accordance to the viscose process. In this case the spin bath for the wet spinning step can be either acidic or alcoholic to yield the pure cellulose. The urea route to soluble cellulose has a lower environmental impact and lower energy consumption than the traditional viscose process. Commercial plants are not yet in use but Neo Industrial Plc's viscose fiber division, Avilon Ltd, plans to convert a viscose production site to the new urea technology and should open 2013, according to their press release in January 2011 [3]. One major advantage with the carbamate route is that the intermediate cellulose carbamate is stable and may be stored or transported without significant degradation. 

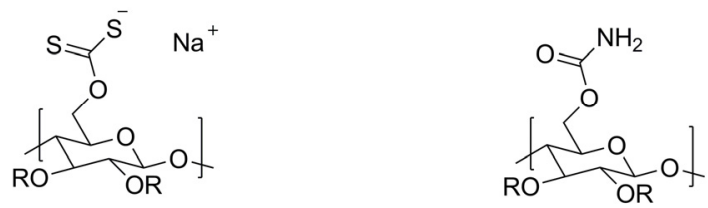

Figure 1. Cellulose xhantogenate (left) with $\mathrm{R}=\mathrm{H}$ or xhanthogenate group and cellulose carbamate (right) with $\mathrm{R}=\mathrm{H}$ or carbamate group.

Common to the cellulose/solvent systems in both the viscose process and the carbamate process is that they involve an intermediate polymer. As already stated, it is in fact not the cellulose itself but a cellulose derivative that is dissolved. This is true for many other solvent systems for cellulose as well, such as DMF/ $\mathrm{N}_{2} \mathrm{O}_{4}$ or $\mathrm{DMSO} / \mathrm{N}_{2} \mathrm{O}_{4}, \mathrm{CF}_{3} \mathrm{COOH}, \mathrm{HCOOH} / \mathrm{H}_{2} \mathrm{SO}_{4}$ and $\mathrm{Cl}_{2} \mathrm{CHCOOH}$. This case may or may not be convenient depending on the application. Direct dissolution of cellulose, without derivatization, is not only necessary in some analytical applications but may also simplify the production of regenerated cellulose since many steps are omitted. A direct solvent will also be considerably more straightforward to recycle since no byproducts are generated, at least not in theory. Today, the only really successful direct solvent system for regenerated cellulose on large scale is the NMMO hydrate even if e.g. both alkali and acid systems are proposed for the same use.

When discussing the dissolution of cellulose in general, and the direct dissolution of it in particular, it is necessary to have a proper understanding of the polymer itself. The properties of cellulose are interesting and unique in many ways. Its dissolution process must also be seen as a result of both kinetics and thermodynamics and as a multidisciplinary chemical challenge, where knowledge in both inorganic and organic chemistry as well as physical chemistry and process engineering is required. To understand, and above all control the dissolution process will be of great importance for future applications of the cellulose polymer.

\section{Macromolecules}

Though the use of both synthetic and modified natural polymers have been of great significance in industry since the $19^{\text {th }}$ century, a reasonably correct understanding of polymer structure was not developed until in the 1920s when Hermann Staudinger proposed a model where polymers, for example cellulose, was composed of covalently linked small repeating units, i.e. the very definition of a polymer today. For this work he received the Nobel Prize in chemistry 1953.

Polymers, with few exceptions, are not homogeneous in length. The degree of polymerization (DP) varies and the molecular weight distribution is one of the major factors influencing the properties of a given polymer.

Some polymers, such as starch, can appear in linear or branched forms. This has great influence on many properties such as crystallinity, solubility, density and as a consequence of this, even thermal and mechanical properties that have direct influence on the industrial 
applications of the product. The repeating units of any polymers are not restricted to being of the same kind all through the chain length. Nor are the branches restricted to being of the same type as their backbone. Alternating monomers yields so called co-polymers or heteropolymers, that can be randomly organized or well defined. Homopolymers may vary in stereochemical configuration to yield isotactic, atactic or syndiotactic polymers if there are any substituents as seen in Figure 2.

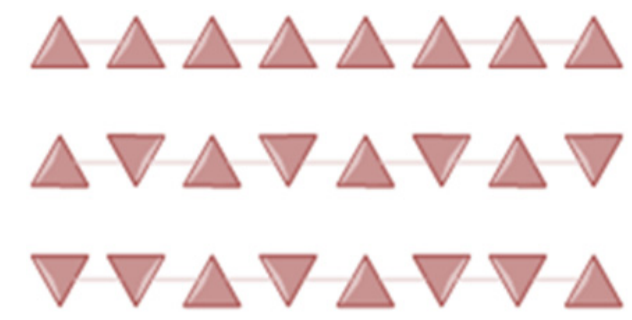

Figure 2. Representation of an isotactic polymer (top) where all monomers have the same stereo/regiochemical configuration, a syndiotactic polymer (middle), where the monomers have alternating positions along the chain and an atactic polymer (bottom) where the configuration of the monomers is random.

Depending on chemical and stereochemical design, polymers experience different interchain forces that, without actual covalent bonding, keep the polymer chains together in the solid state. For electrically neutral polymers, the strongest and most important interchain force is of course hydrogen bond interactions, but dispersion forces may have a significant effect on the polymer bulk too.

\section{Solubility of macromolecules}

In some aspects macromolecules fall under the same rules as all substances when it comes to solubility, in others not at all. Non-polymeric materials dissolve immediately, and in a good solvent the process is controlled mainly by external mass transfer in a stagnant zone near the solid surface. Polymers, on the other hand, undergo a multistep process going from solid to dissolved state. Mass transfer is bidirectional as solvent penetrates the polymer network and swell its outer layer while polymer disentangles from the outermost surface and transfer into the liquid bulk.

As can be intuitively understood, the dissolution rate of polymers decreases with increasing molecular weight. A more intriguing fact is that polydispersity too has a significant effect on the dissolution rate. This effect was investigated in polymethyl methacrylate solutions by Manjkow and others in the late 80s. Polymers of broad molecular weight distributions $\left(\mathrm{M}_{\mathrm{w}} / \mathrm{M}_{\mathrm{n}} \approx 2\right)$ dissolved twice as fast as the monodisperse equivalent with the same $\mathrm{Mn}_{\mathrm{n}}$ [4].

\begin{tabular}{|l|l|l|l|l|l|}
\hline Pure polymer & $\begin{array}{l}\text { Infiltration } \\
\text { layer }\end{array}$ & $\begin{array}{l}\text { Solid swollen } \\
\text { layer }\end{array}$ & Gel layer & Liquid layer & Pure solvent \\
\hline
\end{tabular}

Figure 3. Schematic picture of the composition of the surface layer, adapted from Miller Chou [5]. 
Due to the intrinsic high molecular weight, polymers in general are soluble only in selected solvents. As a result of interchain forces, solubility of polymers is not only dependent on chain length, but also chain-to-chain interaction. Crystallinity and polar groups that may take part in hydrogen bonding thus play a major role in solubility and reactivity of any polymer.

The discussion on thermodynamics of dissolution must begin with Gibbs free energy

$$
\Delta G=\Delta H-T \Delta S
$$

and the idea of an ideal solution, where the enthalpy of mixing and the volume change upon mixing is equal to zero. In a binary solution this would mean that there is no energy gain or loss for the constituents in the solution to interact with either a molecule of its own kind, or a molecule of the other type. This is of course never really true but has some relevance as a simple model. In the case of polymers in solution, the difference in size leads to a non-ideal mixture. In addition to enthalpy, one must take entropy into consideration. For a macromolecule, the gain in entropy is not as great as for the corresponding small molecule. Furthermore, the monomer-to-monomer covalent bond restricts motion and confines the macromolecule within the solvent. This is especially true for stiff polymers, where the conformational freedom does not increase to the same extent as it does for freely rotating polymers when going from solid to dissolved state.

Dissolution can only take place if the dissolved state represents a lower energy than the solid state, meaning that enthalpy of mixing must be balanced by the entropy term. Again, consider glucose and cellulose. The same type of interactions should take place between a glucose molecule and its solvent as between a polymer of glucose and its solvent. The gain in entropy for glucose monomers is far greater than the entropy gain for the glucose polymer. Hence, glucose dissolves easy in e.g. water, while cellulose does not.

A well needed addition to the Gibbs energy equation is the Flory Huggins model (Equation 2) of the thermodynamics of polymers in solution. The free energy of mixing is described by

$$
\Delta G_{m}=R T\left[n_{1} \ln \phi_{1}+n_{2} \ln \phi_{2}+n_{1} \phi_{2} \chi_{12}\right]
$$

where $\Delta \mathrm{Gm}$ is the change in Gibbs free energy, $\mathrm{R}$ is the ideal gas constant, $\mathrm{T}$ is temperature, $\mathrm{n}_{1}$ is the number of moles of the solvent, $\Phi_{1}$ is the volume fraction of solvent, $\mathrm{n}_{2}$ is the number of moles of polymer and $\Phi_{2}$ is the volume fraction of polymer. The parameter chi $(\chi)$ describes the energy of interdispersing polymer and solvent molecules, i.e. both enthalpic and entropic deviations from ideality. The volume fraction $\Phi$ is analogous to the molar fraction, but takes into consideration the size of the molecule. For a small solute, with a size comparable to the size of the solvent molecule the volume fraction can be replaced by molar fraction [6].

This model does not take into account a possible change in volume due to mixing, nor is it applicable in the case of very dilute solutions. For these cases, the theory of excluded volume is used. This is based on the simple assumption that one part of a polymer chain 
cannot occupy the space that is already occupied by another part of the chain. However, the size and shape of dissolved polymers depends on the quality of the solvent. A good solvent is a solvent that coordinates well and strong to the polymer whereas a poor solvent only has weak or almost no coordination to the polymer. The polymer will stretch out in a good solvent and occupy a large volume since interactions with the solvent molecules are favorable. The polymer will contract in a poor solvent, and if the solvent is too poor, eventually precipitate. The so called theta point is reached at the exact conditions where the excluded volume effect is balanced by the solvent. In a theta solvent, the polymer chain reverts to its ideal characteristics, and the chain dimensions are no longer dependent on the solvent choice. In other words, the polymer interacts with the solvent as it would interact with itself, and will have the same chain dimensions as it would have in a polymer melt or amorphous solid phase. This means that analytical measurements in a theta solvent will be independent of solvent and give the "true" value of e.g. radius of gyration [6].

Apart from chemical compatibility, i.e. thermodynamic features of the solvent/solute system, there is kinetics to consider. In the case of a macromolecule such as the cellulose polymer, this is a parameter of critical importance since diffusion rate is ideally inversely proportional to the size of the particle, or in this case the molecule. Hence, in the case of entangled polymers with a severe tendency to self assemble the diffusion rate is drastically retarded. It matters not if the solvent is thermodynamically ideal, if the rate of dissolution is too slow and a solution does not form under a desired amount of time the solvent is useless. Kinetics of dissolution can be manipulated by many different means. Diffusion of large molecules is slow, but addition of heat speeds up the process. In general, addition of heat also lowers the viscosity of liquids such as the solvent and this will be advantageous since it will lower the diffusion resistance. Furthermore, mechanical energy added to the system in form of shear stress will decrease the length of the diffusion path from concentrated polymers solution at the particle surface to the bulk solution. This will not affect the rate of diffusion, but the flux of molecules and thereby the overall kinetics of the dissolution process. This can be understood in a simplified way using Fick's first law shown in equation 3 as linear integrated version.

$$
J=D \frac{\Delta c}{\Delta x}
$$

$\mathrm{J}$ is the flux $[\mathrm{mol} / \mathrm{s}], \mathrm{D}$ is the diffusion coefficient $\left[\mathrm{m}^{2} / \mathrm{s}\right], \Delta \mathrm{c}$ is the concentration gradient from the undissolved particle surface to the bulk solution and $\Delta \mathrm{x}$ is the distance from the particle surface to the bulk, the stagnant layer where mass transport is controlled by diffusion only. Thus, if the distance from the particle surface to the bulk is diminished, the flux of molecules from the solid particle to the bulk solution will increase. It must be stressed that kinetics of polymer dissolution is not by any means as simple as kinetics of dissolution of small molecules, especially when it comes to semi-diluted or concentrated solutions. For example, as the concentration of dissolved polymer increases the viscosity of the solution will increase and this will slow down the process. A basic understanding of the kinetics in a simple system can nevertheless come in handy when it comes to understand the processes in more complex ones. 


\section{Cellulose morphology}

To comprehend the interactions of cellulose and its solvent as well as the dissolution process it is important to have a clear understanding of the polymer itself. Unlike some other biopolymers, like proteins, cellulose in its native form is highly polydisperse and often closely linked to other compounds, e.g. the lignin and hemicelluloses in wood. Apart from this, the polymer structure provides, though at a first glance very symmetric and simple, serious challenges due to its chemical composition and spatial arrangement. From monomer to bulk material, all levels present interesting features that are highly important.

Cellulose was first defined as the remaining part of plant tissue after purification and in the early days of cellulose technology the word cellulose was used also for what is today defined as pulp [7]. Eventually this residue was found to be a carbohydrate very similar to starch, and today it is known that it is a linear syndiotactic polymer (cf. Figure 2) of $\beta$-1,4-glycosidic bond linked D-glucopyranose units, where every other monomer is rotated $180^{\circ}$ with respect to its neighbors. This structure can also be defined, if instead pairs of glucose units, cellobiose, are defined as the repeating unit, as an isotactic polymer. The individual glucose monomers in the cellulose polymer are often referred to as anhydroglucose units, AGU, due to the loss of one water molecule in the polymerization where a hemiacetal reacts with an alcohol to form the acetal bond. From crystallographic [89] and NMR spectroscopic data [10] it has been shown that the six membered glucose monomer takes on a chair conformation. Three hydroxyl groups are present in the AGU, secondary on $\mathrm{C} 2$ and $\mathrm{C} 3$, and a primary on C6. The rotational conformation of the primary alcohol on C6 can be altered, and this has a profound impact on the hydrogen bonding pattern and therefore the crystallinity of the cellulose metastructure [11]. In one end of the polymer the anomeric carbon is involved in a glycosidic bond. This is referred to as the nonreducing end. In the other end of the polymer the anomeric carbon is free to convert to an aldehyde structure, and these two states are in equilibrium. This end is referred to as the reducing end. This chemical polarity of the cellulose chain is important when it comes to its different crystal structures.

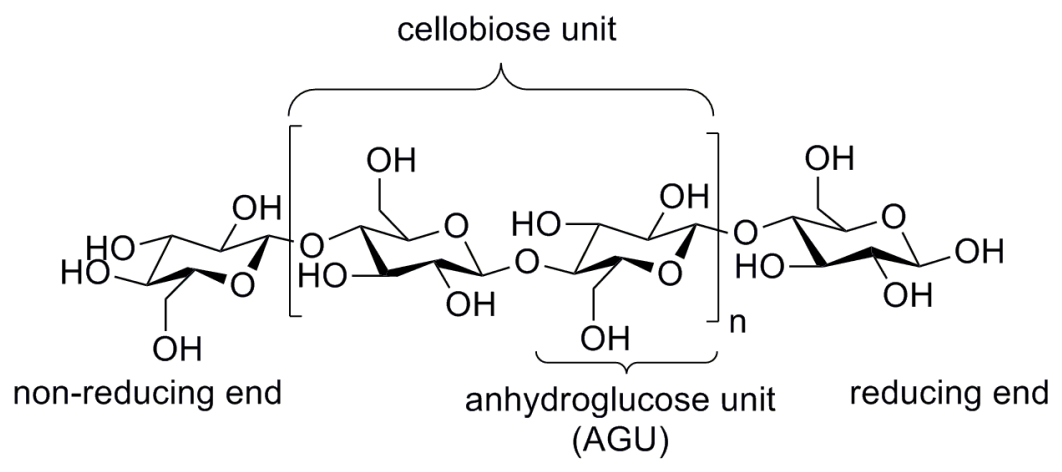

Figure 4. The cellulose polymer chain structure 
The number of AGU units defines the degree of polymerization (DP) of the cellulose. Depending on source, this might vary to a great extent. The DP of various sources including native wood was first determined 1962 [12] to between 9000-10000. Extraction methods and treatment of cellulose might degrade the polymer, and the DP of wood pulp varies between 300-1700 whereas regenerated fibers from cellulose have a degree of polymerization no greater than 250-500.

Polymers in native cellulose are densely packed in a semi ordered structure. Intramolecular hydrogen bonds provide chain stiffness, and intermolecular hydrogen bonds allow for the linear polymers to assemble in sheet structures. These sheets are further packed by hydrophobic interactions into crystals. Crystalline regions in silk, bamboo and wood were confirmed by X-ray spectroscopy already 1913 [13] and ever since, the crystalline structure of celluloses has been studied thoroughly. To this day four main different crystal structures of cellulose have been discovered, namely celluloses I, II, III and IV. Based on the X-ray diffraction data for specimens from the sea algae Valonia ventricosa, native cellulose I was first said to have a triclinic crystal structure of parallel chains [14] but later work showed by solid state NMR spectroscopy that cellulose I can be subdivided into cellulose I $\alpha$ and cellulose I $\beta$ [15-16], where the I $\alpha$ is dominating in bacteria and algae and $\mathrm{I} \beta$ is dominating in higher plants. Recent work on X-ray and neutron diffraction data suggests that only cellulose I $\alpha$ is truly triclinic, while the I $\beta$ form is monoclinic [17]. Cellulose I can easily and irreversible transform into the monoclinic cellulose II by regeneration or alkali treatment, suggesting that the cellulose II is the more stable allomorph [18]. In this transformation, the parallel ordering of polymer chains found in cellulose I is replaced by what seems to be an antiparallel configuration in cellulose II [19]. It is still debated whether this antiparallel ordering is due to chain-folding or interdiffusion of crystallites. Cellulose III and cellulose IV can be reversibly prepared from either cellulose I or cellulose II by various chemical treatments [20].

In its native form, cellulose crystals are never pure. Crystalline regions are interrupted by less ordered structures. Several suggestions on how these crystalline and non-crystalline regions are intermixed have developed over the years, such as single crystals [21] or uniform elementary fibrils [22] but nowadays a so called fringed fibrillar model, developed in the late 50s [23], of the material is widely accepted [24]. In this model the microfibril is not regarded a single crystal but rather a less structured arrangement of non-uniform crystalline segments accompanied by amorphous parts, both longitudinal and lateral.

\section{Solubility of cellulose}

Being a linear homopolymer, cellulose does not appear as a complex structure but its dissolution is in fact very complicated. Many factors contribute to make the cellulose macromolecule insoluble in most common solvents. Cellulose in its native form is often a very long polymer and high DP inevitably leads to decreased solubility due to decreased entropic gain in the dissolution process as already discussed. Glucose, cellobiose and any oligomer of cellulose structure up to around a DP of less than 10 is soluble in simple 
solvents such as water and cellulose is not, so this is indeed a relevant factor. Furthermore, the interactions between the cellulose molecules provide a challenge. Three hydroxyl groups per AGU make complex patterns of hydrogen bonds possible. To break these, solvents with high hydrogen bonding capacity are necessary. Quite a few liquids including water are able to swell, but not to dissolve cellulose. Swelling is defined as a process where the liquid molecule penetrates cellulose structure by interacting with the polymer to a certain extent, leaving the volume and physical properties of the cellulose significantly changed but the solid, or semi-solid state remains. Dissolution, on the other hand, completely destroys the supramolecular structure due to superior interaction between solvent and polymer, and results in a clear solution where the polymers are molecularly dispersed. The same liquid may act as a solvent or merely a swelling agent, depending on the conditions used in the experiment. Temperature can be such a determinant parameter.

One way to estimate a new solvent's compatibility is to evaluate the hydrogen bonding and polarizability properties of the solvent. Parameters of the empirical Kamlet-Taft solvatochromic relationship are used to calculate the hydrogen bond donor $(\alpha)$, hydrogen bond acceptor $(\beta)$, and dipolarity/polarizability $\left(\pi^{*}\right)$ properties of solvents as contributing to overall solvent polarity. This is done by UV/Vis spectroscopy to monitor the interactions of the substrate with chosen indicators of e.g. the ones shown in Figure 4. Numerous solvatochromic indicator dyes are available [25]. In many reports where new solvents for cellulose are being evaluated, the Kamlet-Taft parameters are held as highly important [2629]. In Table 1 the solvatochromic parameters $\alpha, \beta$ and $\pi^{*}$ for cellulose, a cellulose nonsolvent and a cellulose solvent are compared.

\begin{tabular}{|l|c|c|c|}
\hline & $\alpha$ & $\beta$ & $\pi^{*}$ \\
\hline Cellulose (dried) & 1.27 & 0.60 & 0.41 \\
\hline $\mathrm{H}_{2} \mathrm{O}$ & 1.17 & 0.47 & 1.09 \\
\hline $\mathrm{DMAc} / \mathrm{LiCl} \mathrm{(15 \% )}$ & 0.54 & 2.0 & 0.67 \\
\hline
\end{tabular}

Table 1. Kamlet-Taft parameters for cellulose, water and the cellulose solvent system dimethylacetamide (DMAc) with $15 \% \mathrm{LiCl}$ [26, 30-31].
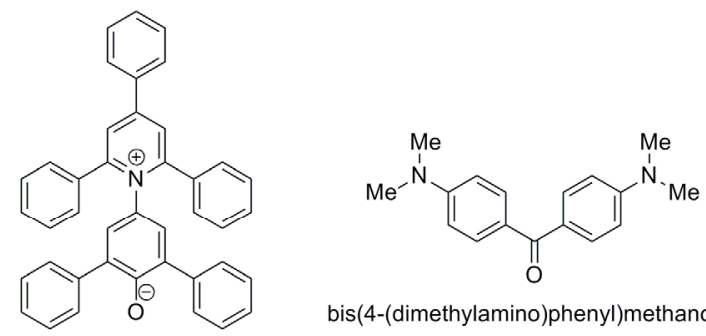

bis(4-(dimethylamino)phenyl)methanone

5'-(2,4,6-triphenylpyridin-1-ium-1-yl)-

$\left[1,1^{\prime}: 3\right.$ ', 1"-terphenyl]-2'-olate

(Reichard's dye)

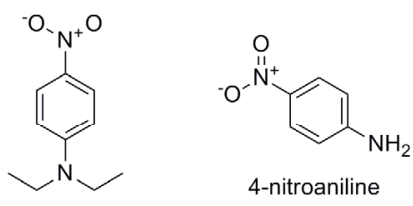

$N, N$-diethyl-4-nitroaniline

Figure 5. Examples of probe dyes for determination of solvatochromic parameters of cellulose solvents. 
Water cannot be used to break the bonds in cellulose, yet both water-water, carbohydratewater and carbohydrate-carbohydrate hydrogen bond strengths are around $5 \mathrm{kcal} / \mathrm{mol}$ [32]. Many forget to take this question into account when they reason about the dissolution of cellulose and its relative insolubility. It is obvious that hydrogen bonding is not the only relevant factor in the quest for a suitable solvent, yet the amphiphilic nature of cellulose is still widely overlooked. The last few years, a few eye-opening papers have taken this matter up to discussion [32-37].
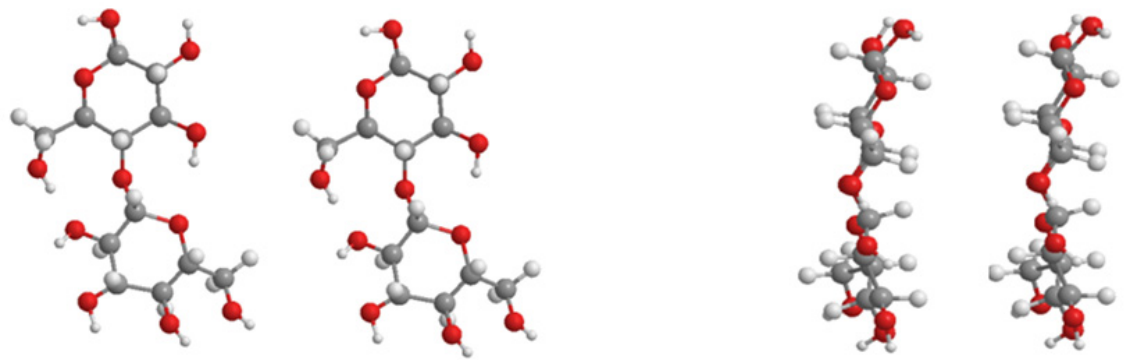

Figure 6. Hydrogen bonds arrange cellulose chains in sheets, and the stacking that forms a three dimensional structure involves hydrophobic interactions.

A relatively new approach when trying to understand molecular interactions is computer simulations and modeling. Some very recently published papers describe this method, showing molecular origins of the recalcitrance of biomass in the terms of decrystallization and dissolution, and showing quantitatively the need for taking cellulose amphiphilicity into account [36-38]. For comparison it may be useful to study cyclodextrins. Typical cyclodextrins are oligosaccharides made up from six to eight $1 \overrightarrow{4}$ linked monosaccharides in a torus and are produced from starch but since starch as cellulose is built up from glucose, this may still serve as a model. Cyclodextrins are water soluble, but the arrangements of hydroxyl groups provide a pronounced amphiphilicity.

The inclusion or the interior of the sugar macro ring is if not fully hydrophobic at least significantly less hydrophilic than the outer part of the structure. As a result of this, cyclodextrins may serve as the host in inclusion complexes. Unusual hydrogen bonding patterns take place inside the cyclodextrin, due to the confined space and the hydrophobic nature of the torus, which was shown by Bezel et al. in a neutron scattering study [39]. This relates to and partly explains the concept of "high energy water" i.e. the water trapped in the cyclodextrin ring in a water solution which upon release by addition of a more hydrophobic substance contributes to a favorable enthalpy change. The driving force for inclusion of a hydrophobic substance in a cyclodextrin ring should be considered an "atypical" hydrophobic interaction, since it is not entropy driven [40]. An extensive overview of cyclodextrins as inclusion complexes was published by Clarke et al. and explains many aspects of the amphiphilicity of these substances [41]. 
The alpha, beta and gamma cyclodextrins with six, seven and eight glucose units in their ring as shown in Figure 6 have all been granted GRAS (generally recognized as safe)-status by the American Food and Drug Administration (FDA). This is useful for many purposes where a hydrophobic compound, or part of a compound, needs to be solubilized in water for example in the drug delivery of lipophilic substances. By considering the uses of cyclodextrins, it is obvious that polymers of glucose should have amphiphilic traits. The difference is that these polymers are linear instead of torus shaped, and make up sheets where the hydrophobic interactions are orthogonal to the hydrophilic.

Coming back to the discussion of polymer solubility, it now seems obvious that any reasonable solvent for cellulose is one that must overcome the low entropy gain by excellent solvent - polymer interactions. For cellulose that has both hydrophilic and hydrophobic features, i.e. the equatorial $\mathrm{OH}$-groups and the axial $\mathrm{CH}$ groups, a good solvent should contain both a hydrogen bonding part and a hydrophobic part.
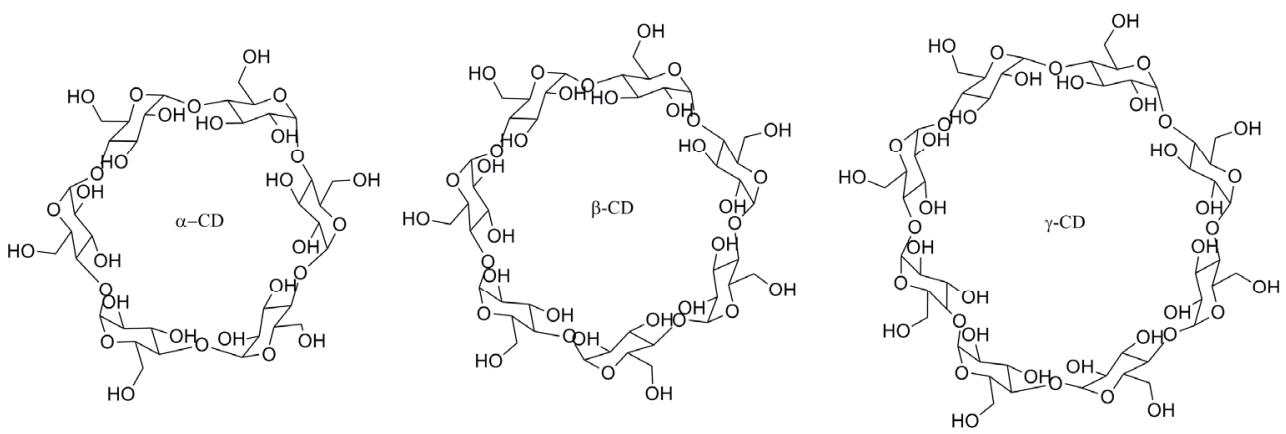

Figure 7. The molecular structure of the six membered alpha cyclodextrin $(\alpha-\mathrm{CD})$, the seven membered beta cyclodextrin $(\beta-C D)$ and the eight membered gamma cyclodextrin $(\gamma-C D)$.

Apart from this, the kinetics of cellulose dissolution in a chosen solvent may be controlled by elevated temperatures, at least up to the point where side reactions such as solvent and/or cellulose will start to degrade. In industrial systems, mechanical energy is added as cellulose dissolution takes part in kneaders that speed up dissolution rate and helps in the disintegration of fibers and gel particles that have been formed as a result of initial swelling. Co-solvents may be added to lower the viscosity of the solutions.

\section{Solvents for cellulose}

Despite the challenges associated with the dissolution of cellulose, numerous options are available. Here the focus lies on direct solvents, i.e. solvents that do not form covalent bonds with the polymer but merely interact by physical means. This distinction between nonderivatizing and derivatizing solvents must be made in order to choose the correct solvent for a specific use. Solvents may further be classified as aqueous or non-aqueous, or as containing halogens or not or whatever else suits the user's purposes. 
Solvents can be further classified based on their number of components. Both unicomponent, bicomponent and tricomponent solvent systems are known and including solvent mixtures the range is even broader. Since many non-derivatizing, or direct, solvents for cellulose includes water, as bulk solvent or as bound water in a salt or organic hydrate, it is not fully satisfactory to make a binary distinction between aqueous and non-aqueous solvents. Instead, solvents could be placed on a continuous scale that represents the amount of water in the system. However, herein the binary view is maintained.

\subsection{Aqueous media}

Being the most green of all chemicals, water is of course an attractive solvent and reaction media. In fact, pure water can actually be used in the field of cellulose technology. Water at around its critical point demonstrates some unique properties and can be an interesting media for various chemistry. Dissolution and hydrolysis of cellulose in subcritical and supercritical water was investigated by Sasaki et al. [42] but the dissolved cellulose in this case was probably shorter fragments and cellooligomers since severe depolymerization must take place before any dissolution can be expected as stated by more recent publications [43-44]. This means that however appealing, it is not yet possible to dissolve high DP cellulose in pure water. Water based solvent systems are plentiful though, and different additives can make water into a very efficient dissolution media. Some of the many alternatives available are listed below.

\subsection{Aqueous alkali}

Mercerization, the process of soaking cellulose in strong alkali to the extent that the crystal structure changes from cellulose I to cellulose II, is one of the most technically relevant processes in cellulose technology and is used to activate the hydroxyl groups of cellulose for further modification and/or dissolution. Cellulose is partly soluble in an aqueous solution of sodium hydroxide in a concentration of about $10 \% \mathrm{w} / \mathrm{w}$. The amount of cellulose that is soluble in $\mathrm{NaOH} / \mathrm{H}_{2} \mathrm{O}$ depends on degree of polymerization and also mode of crystallinity [45]. Isogai investigated the solubility of cellulose from several sources but never succeeded in preparing cellulose solutions of higher concentrations than $5 \%$ [46]. A method for complete dissolution of cellulose in lye solutions was also patented in 1994 [47]. For cellulose to dissolve in alkaline aqueous media, it needs to be cooled well below room temperature. Soube et al. completed the phase diagram for the ternary system cellulose $/ \mathrm{NaOH} / \mathrm{H}_{2} \mathrm{O}$ [48]. Taking the amphiphilic properties of cellulose into account, it is not surprising that it has been shown that cellulose in $\mathrm{NaOH} / \mathrm{H}_{2} \mathrm{O}$ is in fact not completely dissolved but forms aggregates [49].

More recently, sodium hydroxide solutions with different additives have turned out to dissolve cellulose more efficiently than the binary $\mathrm{NaOH} / \mathrm{H}_{2} \mathrm{O}$ system itself. Such additives are for example poly(ethylene glycol) (PEG) [50-51] and urea [52] and/or thiourea [53-55]. The fact that sodium hydroxide, PEG and urea are all environmentally friendly and pose low toxicity towards humans and animals makes these solvent systems interesting for large 
scale applications. However, mixed systems always pose high demands on recovery systems, and the amount of additives needed in these systems makes recovery and reuse quite necessary.<smiles>COCCO</smiles><smiles>NC(N)=O</smiles><smiles>NC(=S)S</smiles>

Figure 8. Additives in aqueous alkali solvents for cellulose. From left to right; poly(ethylene glycol), urea, thiourea.

Mechanical or chemical pretreatment is necessary for the dissolution to be efficient enough for industrial needs [56]. Several studies of cellulose in the aqueous $\mathrm{NaOH} /$ urea system using e.g. ${ }^{13} \mathrm{C}$ NMR, ${ }^{15} \mathrm{~N}$ NMR, ${ }^{1} \mathrm{H}$ NMR, FTIR, small angle neutron scattering and wide angle $\mathrm{X}$-ray scattering suggest that the dissolution mechanism is based on the hydrates of $\mathrm{NaOH}$ that in low temperatures are able to form hydrogen bonds with the cellulose chain, while the urea molecules surrounds the cellulose $/ \mathrm{NaOH} / \mathrm{H}_{2} \mathrm{O}$ inclusion complex, screening it from other cellulose molecules and thereby prevent cellulose aggregation [57-59]. Being a hydrotrope, urea is expected to increase the solubility of a poorly water soluble solute in aqueous solutions. This is explained by the ability of hydrotropes to break water structures, i.e. the effect is explained by urea - water interactions, and/or a tendency of hydrotropes to interact with the solute itself by hydrophobic interactions. Interestingly, in the case of cellulose in aqueous $\mathrm{NaOH} /$ urea, no direct evidence of interaction between urea and cellulose was found. In the original $\mathrm{NaOH} / \mathrm{PEG} / \mathrm{H}_{2} \mathrm{O}$ publication by Yan and Gao [50] the dissolution mechanism was suggested to be similar to that in $\mathrm{NaOH} / \mathrm{urea} / \mathrm{H}_{2} \mathrm{O}$. It was proposed that the solution is stabilized by polyethylene glycol chains, here acting as hydrogen bonding acceptors. It has also been suggested that the mechanism for dissolution in these types of solvent mixture relates to a charging up of the cellulose, i.e. turning it into a polyelectrolyte [32].

The solutions of cellulose in aqueous alkali with urea and/or thiourea are being thoroughly investigated for shaping purposes, i.e. regeneration of cellulose into fibers, membranes or similar. Recently, Yang et al. prepared high performance flexible films from different cellulose sources in a solvent of alkali and urea [60]. The films showed good gas barrier properties over the entire relative humidity range, and always one order of magnitude lower gas permeability than cellophane films which are prepared via the viscose process. Compared to conventional films from poly(ethylene) and poly(propylene), all cellulose films show increased water vapor permeability, but this is expected due to the intrinsic hydrophilicity of the polysaccharide structure. Regenerated cellulose fibers similar to viscose or Lyocell fiber have been wet spun from solutions of $\mathrm{NaOH} /$ urea [61] and $\mathrm{NaOH}$ /thiourea solutions [62-63].

The procedure for dissolving cellulose in aqueous alkali/urea-systems is based on a freezethaw method. The solvent is pre-cooled to below the freezing point of water before cellulose is added and kept cold until complete dissolution of the polymer [64]. Regeneration takes 
place by precipitation in e.g. dilute $\mathrm{H}_{2} \mathrm{SO}_{4}$, ethanol, butanol or acetone [60]. Lithium hydroxide and potassium hydroxide are expected to have a similar effect as sodium hydroxide. A strong impact of the choice of salt has been observed, and the dissolution power of the different systems is in the order $\mathrm{LiOH} /$ urea $>\mathrm{NaOH} / \mathrm{urea}>\mathrm{KOH} /$ urea. Both $\mathrm{LiOH}$ and $\mathrm{NaOH}$ in combination with urea are able to rapidly dissolve cellulose, while $\mathrm{KOH}$ is not [64].

The possibility to perform homogeneous reaction in aqueous alkali/urea systems has not been neglected and it has been shown to be a stable media for etherification reactions. Carboxymethylation of cotton linters and microcrystalline cellulose was carried out in lithium hydroxide with urea and the degree of substitution could be controlled [65]. The product was water soluble CMC. Another important cellulose derivative, namely hydroxyethyl cellulose, was prepared from cotton linters by homogeneous reaction in sodium hydroxide with urea under mild conditions [66].

\subsection{Inorganic metal complexes}

One interesting group of solvents is the one of inorganic metal complexes. The complexes are of transition metal ions and nitrous ligands. Some of the most common ones [67] are listed in Table 2.

As in many cases with solutions of transition metal complexes, most of the cellulose solvents in this group are strongly colored. This is true for example with Cuoxam, Nitren and Cuen which all are deep blue, while Pden only displays a weak yellow color. The color of the solvent or in some cases the cellulose - metal complex in itself may cause problems in analytical applications where light scattering or refractive index is used [68].

\begin{tabular}{|l|l|}
\hline Cadoxen & {$\left[\mathrm{Cd}\left(\mathrm{H}_{2} \mathrm{~N}_{(}\left(\mathrm{CH}_{2}\right)_{2} \mathrm{NH}_{2}\right)_{3}\right](\mathrm{OH})_{2}$} \\
\hline Cdtren & {$\left[\mathrm{Cd}\left(\mathrm{NH}_{2} \mathrm{CH}_{2} \mathrm{CH}_{2}\right)_{3} \mathrm{~N}\right](\mathrm{OH})_{2}$} \\
\hline Cooxen & {$\left[\mathrm{Co}\left(\mathrm{H}_{2} \mathrm{~N}_{(}\left(\mathrm{CH}_{2}\right)_{2} \mathrm{NH}_{2}\right)_{2}\right](\mathrm{OH})_{2}$} \\
\hline Cupren & {$\left[\mathrm{Cu}\left(\mathrm{H}_{2} \mathrm{~N}_{(}\left(\mathrm{CH}_{2}\right)_{3} \mathrm{NH}_{2}\right)_{2}\right](\mathrm{OH})_{2}$} \\
\hline Cuam/Cuoxam/Schweitzer's reagent & {$\left[\mathrm{Cu}\left(\mathrm{NH}_{3}\right)_{4}\right](\mathrm{OH})_{2}$} \\
\hline Cuen & {$\left[\mathrm{Cu}\left(\mathrm{H}_{2} \mathrm{~N}_{2}\left(\mathrm{CH}_{2}\right)_{2} \mathrm{NH}_{2}\right)_{2}\right](\mathrm{OH})_{2}$} \\
\hline Nioxam & {$\left[\mathrm{Ni}\left(\mathrm{NH}_{3}\right)_{6}\right]\left(\mathrm{OH}_{2}\right)_{2}$} \\
\hline Nioxen & {$\left[\mathrm{Ni}\left(\mathrm{H}_{2} \mathrm{~N}_{(}\left(\mathrm{CH}_{2}\right)_{2} \mathrm{NH}_{2}\right)_{3}\right](\mathrm{OH})_{2}$} \\
\hline Nitren & {$\left[\mathrm{Ni}\left(\mathrm{NH}_{2} \mathrm{CH}_{2} \mathrm{CH}_{2}\right)_{3} \mathrm{~N}\right](\mathrm{OH})_{2}$} \\
\hline Pden & {$\left[\mathrm{Pd}\left(\mathrm{H}_{2} \mathrm{~N}_{(}\left(\mathrm{CH}_{2}\right)_{2} \mathrm{NH}_{2}\right](\mathrm{OH})_{2}\right.$} \\
\hline Zincoxen & {$\left[\mathrm{Zn}\left(\mathrm{H}_{2} \mathrm{~N}_{(}\left(\mathrm{CH}_{2}\right)_{2} \mathrm{NH}_{2}\right)_{2}\right](\mathrm{OH})_{2}$} \\
\hline
\end{tabular}

Table 2. Transition metal complexes with amines or $\mathrm{NH}_{3}$, their common names and chemical formula.

Saalwächter et al. compared several metal complexes and found that the coordinative binding metal complexes such as Cuoxam, Nitren and Cdtren were most efficient as cellulose solvents. The coordination takes place at the deprotonated olate anions at C2 and C3 at each AGU. Even though the dissolution appears to be to molecular level and via 
interaction with the C3 hydroxyl group, the cellulose chain stiffness appears to be considerable. The number of Kuhn segments, i.e. the number of efficient straight segments seconded by kinks, per polymer rarely exceeds 50 [68] which means that several monomers are assembled in rod like structures before an actual bend.

Apart from complex coordination, metal complexes can interact with cellulose via pure Coloumb interactions. This is the case for Cuen [68], but not for Pden which forms square planar complexes with the AGUs of cellulose as with any other ligand [69-70].

Aqueous inorganic salts or metal complexes can also be used for dissolution and regeneration of cellulose. The Cupro process, using cuprammonium hydroxide (Cuam) as solvent, was invented already in the year 1890 and is still used today, although not in a huge scale [71]. The solvents have also proven viable reaction media. For example, completely homogeneous etherification of cellulose may be performed in Nitren to produce carboxymethyl cellulose in a one-phase-reaction with a regioselectivity and substitution pattern similar to the carboxymethyl cellulose obtained from commercial routes in $\mathrm{NaOH}$ slurries [72]. Unfortunately, some of the representatives of the inorganic metal complex based solvents initiate severe cellulose depolymerization in the presence of even traces of oxygen [73].

\subsection{Molten inorganic salt hydrates/concentrated inorganic salt solutions}

Molten inorganic salts have been pursued as cellulose solvents and reaction media for close to 100 years now and some are indeed able to dissolve cellulose without pretreatment and in reasonable concentrations. Both pure salt hydrates and mixtures of different salt hydrates as well as certain concentrated inorganic salt solutions may swell or dissolve cellulose [74]. The most commonly used solvents in this class are $\mathrm{MgCl}_{2}{ }^{*} 6 \mathrm{H}_{2} \mathrm{O}, \mathrm{LiCl}^{*} 5 \mathrm{H}_{2} \mathrm{O}, \mathrm{LiClO}_{4}{ }^{*} 3 \mathrm{H}_{2} \mathrm{O}$, $\mathrm{ZnCl}_{2}{ }^{*} 4 \mathrm{H}_{2} \mathrm{O}, \mathrm{ZnCl}_{2} / \mathrm{H}_{2} \mathrm{O}, \mathrm{LiSCN}$ and $\mathrm{Ca}(\mathrm{SCN})_{2} / \mathrm{H}_{2} \mathrm{O}$ with or without adition of the sodium or potassium thiocyanate salt [75]. $\mathrm{LiClO}_{4} * 3 \mathrm{H}_{2} \mathrm{O}$ is an extremely efficient solvent and cellulose in this particular salt gives clear solutions within a few minutes.

The dissolution process of cellulose in the aqueous $\mathrm{Ca}(\mathrm{SCN})_{2}$ solvent system was examined using IR spectroscopy by Hattori et al. and it seems to be based on complex formation and an addition compound between cellulose and the thiocyanate anion [76] but curiously enough, the crystallinity of regenerated cellulose product appears to depend on what kind of precipitation agent is used. In water, only cellulose II is recovered, but in methanol the product is mainly cellulose I. Upon precipitation in acetone the product is amorphous [77]. The interaction between cellulose and salt hydrates have also been examined using Raman spectroscopy [74], and of course different NMR spectroscopy techniques [78]. The variation in dissolution processes in different molten salt hydrates was again thoroughly investigated by e.g. ${ }^{13} \mathrm{C}$ NMR spectroscopy and discussed by Leipner et al [79].

Homogeneous reactions to obtain cellulose derivatives may be carried out in molten inorganic salt hydrates. Heinze with coworkers reported successful carboxymethylation of cellulose in $\mathrm{LiClO}_{4}{ }^{*} 3 \mathrm{H}_{2} \mathrm{O}$ with varying degree of substitution, and a statistical distribution of 
substituents, showing that no part of the cellulose polymer was inaccessible to the reagents $[72,80]$. Esterification in the form of acetylation in the molten inorganic salt $\mathrm{LiClO}_{4}{ }^{*} 3 \mathrm{H}_{2} \mathrm{O}$ and the eutectic mixture of $\mathrm{NaSCN} / \mathrm{KSCN} / \mathrm{LiSCN}^{*} 2 \mathrm{H}_{2} \mathrm{O}$, as well as deacetylation reactions of cellulose triacetate in the concentrated salt solution of $\mathrm{ZnCl}_{2} / \mathrm{H}_{2} \mathrm{O}$ has been reported [81]. The acetylation reactions were performed with various acetylating agents such as vinyl acetate and acetic anhydride.

\subsection{Acidic solutions of cellulose}

It is sometimes claimed that mineral acids are able to dissolve cellulose. However, this must be put in context. Dilute acids swell cellulose, but dissolution can only be achieved using higher concentrations of acids and is expected to be associated with severe, if not complete, chain degradation over time if temperature is not kept very low. The concept of level-off degree of polymerization (LODP) was introduced as the chain length of cellulose after treatment in $2.5 \mathrm{~N}$ hydrochloric acid [82-83]. If the hydrolysis is allowed to continue the degree of polymerization will eventually reach the LODP which is thought to reflect the longitudinal size of the native cellulose crystals, since non-crystalline areas are preferably hydrolyzed over the crystallites.

Concentrated mineral acids such as hydrochloric acid, phosphoric acid or mixed acids are utilized as degradation media to prepare cellodextrins, short chained cellulose oligomers [84-87]. Phosphoric acids, with or without additives such as organic acids as a potent solvent for cellulose was patented already back in 1927 [88].

The transition from swelling to dissolution of cellulose in o-phosphoric acid, and its effect on the cellulose accessibility to enzymatic hydrolysis, was studied by Zhang et al. and dissolution took place without severe hydrolysis under the conditions used [89]. As often, water plays a crucial role in the dissolution behavior of cellulose in this solvent. Phosphoric acid is quite unique being triprotic and due to its ability to form dimers and even polymers. The composition of the acid is usually expressed in $\mathrm{P}_{2} \mathrm{O}_{5}$-concentration, which, at a concentration exceeding $74 \%$ is anhydrous (superphosphoric acid). Thus, mixing different species of phosphoric acids may give a powerful cellulose solvent, claimed to rapidly dissolve up to $38 \% \mathrm{w} / \mathrm{w}$ cellulose. This was shown recently and from these anisotropic solutions of cellulose with a DP of 700-800 in water free phosphoric acid, spinning dopes for production of textile fibers with only moderate chain degradation could be prepared. Fibers can be spun by air gap spinning in acetone and neutralized by $\mathrm{Na}_{2} \mathrm{CO}_{3}$. The resulting yarn showed extraordinary tenacity [90-91].

Carboxylic acids are not successfully used as direct dissolution media for cellulose. The acidity is low, and the acids are likely to react with the cellulose, resulting in cellulose derivatives that must be converted to pure cellulose in a second step. Acids in this group that may be used as solvents for cellulose include trifluoroacetic acid, dichloroacetic acid and formic acid with or without addition of sulfuric acid [92]. The dissolution is much faster if sulfuric acid is used as a catalyst. However, the polymers dissolved in these acids are not 
cellulose but the corresponding cellulose derivative, meaning these are in fact not direct solvents for cellulose but rather derivatizing solvents. Moreover, common for the cellulose derivatives produced via this route is unsurprisingly that they show hydrolytic instability.

\subsection{Non aqueous media}

In 1934, Charles Graenacher reported the first non-aqueous direct solvent for cellulose in his patent where he applied N-alkylpyridinium salts not only as fairly efficient dissolution media but also for homogeneous reaction [93]. Since then a wide distribution of non aqueous media for cellulose treatment have developed, for uses both within industry and academia.

\subsection{DMAc/LiCl}

One of the most frequently used solvent systems for cellulose and other polysaccharides when it comes to homogenous modification and analytical work such as size exclusion chromatography is the dimethyl acetamide/lithium chloride mixture [94-96] first patented by McCormic in the early 80 s [97]. The $\mathrm{DMAc} / \mathrm{LiCl}$ solvent system is very efficient and will dissolve even high molecular weight cellulose like cotton linters or bacterial cellulose with negligible chain degradation at moderate temperatures. Besides that, major advantages are that the solutions are colorless and compatible with GPC columns.

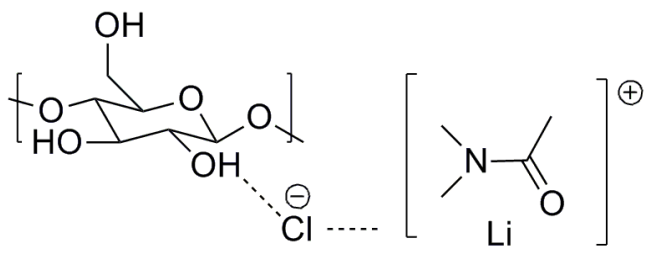

Figure 9. Proposed interaction between solvent and polymer acting as the dissolution mechanism of the system cellulose in DMAc/LiCl, adapted from McCormick, Callais et al. 1985.

The DMAc/LiCl solvent system for cellulose seems to be very specific in its interaction. Neither DMAc with other lithium salts nor DMAc with other chloride salts seem to work in the same way and not even the similar solvent dimethyl formamide with addition of $\mathrm{LiCl}$. The mechanism proposed by McCormick was that hydroxyl groups of cellulose interact with a lithium - DMAc macrocation via hydrogen bonding bridged by the chloride anion. The lithium cation interacts with the carbonyl oxygen via ion - dipole interaction [98]. For this interaction to take place, no cellulose bound water can be present. As a consequence of this, solvent exchange of the cellulose or distillation of the DMAc/ $\mathrm{LiCl} / \mathrm{cell}$ lulose system is often necessary. This is a time and solvent demanding step and is one reason why this solvent system may not be preferred outside laboratory scale conditions. Moreover, the solvent itself needs to be dry, since it is easily disturbed by water impurities [99]. Despite early suggestions, the dissolution mechanism is disputed and still not completely understood. However, the DMAc molecule is not able to form hydrogen bonds to any large 
extent, and that should leave the inorganic ions of the mixtures highly active and free to interact with the polysaccharide instead [94].

This solvent system has been suggested for preparing regenerated cellulose. For example, cellulose beads for support in columns used for liquid chromatography have successfully been produced from $\mathrm{DMAc} / \mathrm{LiCl}$ solutions and due to the efficiency of the solvent it was possible to optimize the bead performance by adjusting DP and concentration of cellulose [100]. DMAc/LiCl is also suitable for homogeneous derivatization of cellulose. As a "true" solvent where no covalent bonding between solvent and solute takes place, the cellulose is fully susceptible to reaction with other molecules [101-102].

In spite of its many uses, this solvent system experiences some problems. In size exclusion chromatography, unwanted effects have been noticed [103] and under thermal stress the cellulose solutions in DMAc/LiCl may fail to remain inert [104].

\subsection{DMSO/TBAF}

A new and very powerful solvent for cellulose consists of a mixture of dimethylsulfoxide (DMSO) and tetrabutylammonium fluoride (TBAF). It is an efficient solvent and can dissolve cellulose with a DP of up to 1200 within one hour at $60{ }^{\circ} \mathrm{C}$ [105]. So far, the DMSO/TBAF solvent system has been used mostly for analytical purposes e.g. NMR and GPC but also for homogenous reactions for chemical modification of cellulose, both in labscale only. Both etherifications and esterifications have been pursued with varying success [106-110].<smiles>CS(C)=O</smiles>

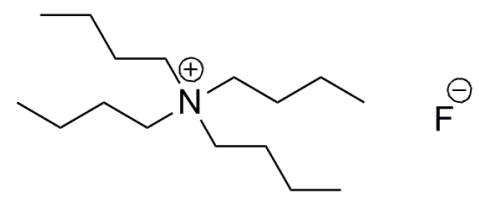

Figure 10. Dimethylsulfoxide (left) and tetrabutylammonium fluoride (right), here represented as anhydrous.

TBAF is a very hygroscopic salt and water content in DMSO/TBAF/cellulose solutions may play a crucial role, depending on circumstances. Anhydrous TBAF is unstable [111-112] but TBAF with water content up to the trihydrate are excellent cellulose solvents, while higher water content is not tolerated. Other ammonium fluorides might be applicable as well [105].

\subsection{N-Methylmorpholine-N-oxide: NMMO}

Indisputable the most industrially successful of all non-derivatizing cellulose solvents is the $\mathrm{N}$-methylmorpholine-N-oxide, commonly known as NMMO. Due to its ability to dissolve high concentrations of cellulose directly and without alteration of the chemical properties of the cellulose chain, as well as the possibility to recycle more than $99 \%$ of the solvent after usage, this particular solvent has proven to be a viable commercial solvent system. Fibers 
produced from this solvent also show exceptional mechanical and tactile properties, making NMMO a serious competition to the old but incredibly successful solvent system $\mathrm{NaOH} / \mathrm{CS}_{2}$ used in the viscose process. The NMMO solvent system has clear advantages in that it is non-derivatizing, since many process steps may be left out.

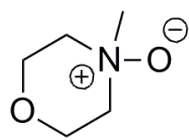

Figure 11. $\mathrm{N}$-methylmorpholine-N-oxide, a cyclic, aliphatic tertiary amine oxide.

NMMO is completely soluble in water, and as a pure substance it is extremely hygroscopic. The high polarity of the $\mathrm{N}-\mathrm{O}$ bond also results in a pronounced ability to form hydrogen bonds. There are two stable hydrates of $\mathrm{NMMO}$, the monohydrate $\mathrm{NMMO}^{*} \mathrm{H}_{2} \mathrm{O}$ and the 2.5hydrate $\mathrm{NMMO}^{*} 2.5 \mathrm{H}_{2} \mathrm{O}$. As cellulose solvent the $\mathrm{NMMO}^{*} \mathrm{H}_{2} \mathrm{O}$ is preferred, and cellulose is soluble all the way up to $\mathrm{NMMO}^{*} 1.2 \mathrm{H}_{2} \mathrm{O}$ while for higher amounts of water precipitation of cellulose takes place. The NMMO oxygen is able to form two hydrogen bonds with nearby hydroxyl groups such in water or cellulose [113]. Hence, the monohydrate can dissolve cellulose while the 2.5-hydrate cannot. The competition of water and cellulose for these hydrogen bonds is the central feature of a whole industry based on dissolution and regeneration of cellulose in the NMMO system.

The procedure for dissolving cellulose in NMMO usually includes a first step where a suspension of cellulose in NMMO and a large excess of water is well mixed. The excess water provides low viscosity and thereby superior mixing. Surplus water is then removed by heat between 100 and $120^{\circ} \mathrm{C}$ and reduced pressure until the point of complete cellulose dissolution is reached and the spinning dope is in its final form of approximately $14 \%$ cellulose, $10 \%$ water and $76 \%$ NMMO.

The dissolution process of cellulose in NMMO at elevated temperatures is performed under strictly controlled conditions, since NMMO is thermally unstable. The $\mathrm{N}-\mathrm{O}$ bond is energy rich and upon cleavage releases $222 \mathrm{~kJ} / \mathrm{mol}$. Furthermore, NMMO is an oxidant and is sensitive to all forms of catalytic impurities in the dope. NMMO was first considered as an unproblematic solvent without byproduct in the process of dissolving cellulose, but as the knowledge of the possible side reactions in the cellulose/NMMO have increased, the understanding of industrial challenges has improved [114-116]. Due to the reactivity of NMMO and the severe degradation of cellulose that may be the result of this, stabilizers must be added already in the beginning of the dissolution process. Such stabilizers are for example propyl gallate, which is the most known. This compound forms a strongly colored chromophore during usage, and other stabilizers are currently being investigated [117]. The degradation of NMMO and subsequent side reactions may include N-methylmorpholine, morpholine and formaldehyde. Some reactions are induced by transition metal ions such as iron and copper, why these must be strictly excluded from the process [118]. 
To be able to prepare cellulose solutions in NMMO without stabilizers and without chain degradation, temperature and/or time must be kept low and while this is not doable under commercial conditions, stabilizers are a crucial part of the process. To succeed without stabilizers, high shear must be applied throughout the dissolution and immediately subsequent spinning process [119]. This accelerates the dissolution process and results in a smooth dissolution without undissolved gel particles. Mechanical energy added to the system might have the role of facilitating breakage of cellulose - cellulose intermolecular bonds, enabling solvent molecules to coordinate to the polymer instead. In addition, the apparent viscosity decreases with shear stress due to cellulose alignment, as expected in non-Newtonian polymer solutions. Viscosity is of course also dependent on cellulose concentration and degree of polymerization of chosen substrate.

NMMO is now successfully applied as a non derivatizing cellulose solvent on industrial scale, and a huge amount of research is available on the subtle details on the interactions between polymers and solvent. For example, activation of cellulose seems to play a significant role in the aggregation behavior of cellulose in the NMMO monohydrate solution [120].

\subsection{Ionic liquids}

This broad class of solvents comprises low melting salts with an organic cation and an organic or inorganic anion. Several comprehensive overviews of the field have been published since 2002 when Swatloski found the neat imidazolium salt 1-butyl-3-methyl imidazolium chloride (BMIMCl) to dissolve cellulose [121]. As previously mentioned, Graenacher found already in 1934 that liquefied quaternary ammonium salts, alone or diluted in suitable solvents, could dissolve cellulose. He worked mostly with pyridinium chlorides, but at the time this did not attract the attention it might have deserved [93]. Ionic liquids (IL) represent chemicals simply defined as organic salts with a melting point below $100{ }^{\circ} \mathrm{C}$ and are not limited to being solvents. Room temperature ionic liquids (RTIL) are often considered the second generation of ionic liquids. The possibility to pair anions with cations yields an almost endless library of potential ionic liquids, and the possibilities to adjust chemical and physical properties of the resulting salts are immense. Since the late 1990s, the interest in ionic liquids has grown fast. Ionic liquids have now penetrated many areas of research and industrial applications of ionic liquids can be found in as wide spread areas as pharmaceutics, analytical chemistry, separation and extraction, materials science and as electrolytes in batteries. For cellulose applications the topic is an ever growing area of research. This relatively new solvent class has already shown great versatility in the field of cellulose technology, including dissolution for regeneration purposes [122-123], homogeneous derivatization [124], and biomass processing including wood component separation [125-127].

The ionic liquids that are able to dissolve cellulose include several classes of cations, and a multitude of anions. Some of the most common cations are imidazolium, pyridinium, ammonium and phosphonium derivatives, shown in Figure 12. The most popular cation 
used today is the imidazolium cation with different alkyl substituents. The effect of alkyl chain length on the cellulose dissolution ability was acknowledged already 2002 by Swatloski and has since then been observed by several groups [128-129]. Studies on the imidazolium cation itself, not taking into account its properties as a solvent, recently explained in detail the effect of cation symmetry and found effects on e.g. glass temperature, viscosity and ion mobility [130]. The asymmetrical cation provides the ionic liquid with lower viscosity, which indeed is an important feature for a solvent.<smiles>[R][n+]1ccn(C)c1</smiles>

imidazolium<smiles></smiles>

pyridinium<smiles>[R]N([R3])[R]</smiles>

ammonium<smiles>[R][PH]([R])([R])[R]</smiles>

phosphonium

Figure 12. Technically relevant ionic liquid cations for cellulose processing.

The dissolution mechanism of cellulose in ionic liquids has long been argued to be all about hydrogen bond interaction. Several studies have confirmed that the anion of the ionic liquid penetrates the cellulose structure and dissembles the native cellulose structure by competitive hydrogen bonding [131-133]. The anion acts as a hydrogen bond acceptor and the cation as a hydrogen bond donor.

In his original article Swatloski argued that hydrogen bond capability, and therefore the ability to dissolve cellulose, was directly related to the anion concentration in the close proximity of the polymer. This was said to be the reason for the fact that the butyl imidazolium salt but not the corresponding salts with higher alkyl chains could dissolve cellulose. Smaller cations simply allow for more anions to crowd around the cellulose chain [128]. The role of the cation in the dissolution mechanism is still disputed. Some simply leave the cation out of the discussion while others attributes the cation a more prominent role, e.g. as electron acceptor and hydrogen bond donor as according to Feng and Chen, c.f. Figure 12. In that case, both the cation and the anion need to be small enough to reach the hydroxyl groups of the cellulose, forming a electron donor - electron acceptor complex, break the polysaccharide - polysaccharide interactions and finally solubilize the polymer [134]. Proof of this is claimed to be the change in cellulose dissolution capability in imidazolium salts when the acidic proton on C2 is replaced by a methyl group [123].

Viscosity and other rheological properties are always important when working with polymer melts or solutions. One feature to examine is the Mark-Houwink parameters which relate the molecular weight of the polymer with the intrinsic viscosity of the solution according to the simple expression

$$
[\eta]=K M^{\alpha}
$$

where $[\eta]$ is the intrinsic viscosity and $\mathrm{M}$ is the molecular weight if the polymer. $\mathrm{K}$ and $\alpha$ are the so called Mark-Houwink parameters. An indication of the polymer shape and indirectly 
a measure of the solvent quality can be acquired from these parameters. Cellulose solutions in ionic liquids have been studied by Gericke and co-workers who examined the MarkHouwink parameters for cellulose/1-ethyl-3-methyl-imidazolium acetate (EMIMAc) solutions, and report $\alpha$-values of $0.4-0.6$ in the temperature range of $0-100{ }^{\circ} \mathrm{C}$. A value of $\alpha$ around 0.8 indicates a "good" solvent and in general, $\alpha$-values of 0.65 to $\sim 1$ have been reported for other cellulose solutions [135].

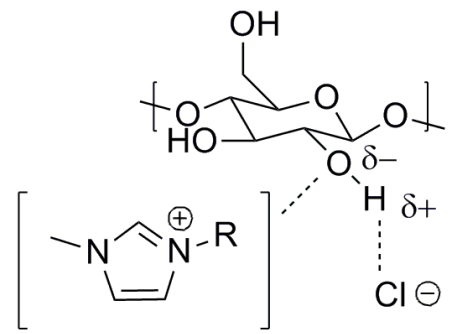

Figure 13. Interaction between cellulose and imidazolium type ionic liquid, adapted from Feng and co workers [134].

It has been shown numerous times that ionic liquids can be used as a reaction media for homogeneous derivatization as well as for dissolution of cellulose. Further, it has been proposed that due to their good dissolution properties, the use of ionic liquids can aid in control of degree of substitution in for example acetylation and tosylation reactions using various ionic liquids, reaction conditions and reactants [136-138]. Unlike in DMAc/LiCl solutions, no catalyst seems to be needed. The degree of substitution be controlled and a very wide range of DS can be achieved [136]. Silylations of cellulose in solutions of BMIMCl and EMIMAc using hexamethyldisilazane as silylating agent with high yields were also recently reported. Degree of substitution was controlled by reaction conditions and DS = 3 were achievable [139].

Ionic liquids as reaction media for homogeneous derivatization of cellulose turn out to be efficient enough to possibly compete with today's heterogeneous reaction routes. With optimization of reaction conditions the possibilities to control DS and possibly even substitution pattern opens up for production of new materials based on cellulose. One of the most important cellulose derivatives is still the cellulose acetate. Acetylation of cellulose can be performed using the ionic liquid not only as a solvent but as the actual reagent [140]. This was first discovered as an unexpected side reaction when in fact the goal was to react cellulose with acid chlorides, trityl chlorides and tosyl chlorides. The resulting polymer was acetylated, meaning that parts of the solvent, in this case the acetate anions of the ionic liquid EMIMAc, are consumed. In large scale applications this might turn out to be a serious problem, since recycling of the solvent requires that it does not degrade or react during the process. Not only will the recycling be more complicated due to side products, it will also be incomplete and in large scale application recycling of the solvent is necessary for both economic and environmental sustainability [141]. 
Mixed solvent systems provide further possibilities in cellulose processing. Adding a cosolvent might serve as a means to lower the viscosity of the solution and thereby facilitate fast dissolution rate and overall ease of handling. Mixtures of ionic liquids and organic solvents includes $\mathrm{BMIMCl}$ in 1,3-dimethyl-2-imidazolidinone (DMI) that, thanks to its low viscosity allows for efficient mixing and no agglomeration. This system is claimed to dissolve $10 \%$ cellulose (Avicel) within a few minutes at $100{ }^{\circ} \mathrm{C}$. This behavior is explained by the fact that only a fraction of IL in the proper molecular solvent may shift the solvatochromic Kamlet Taft parameters $\alpha, \beta$ and $\pi^{*}$ to the point where cellulose is dissolved [142]. Remsing and coworkers studied the molecular interactions of $\mathrm{BMIMCl}$ in water and DMSO, respectively, and found that while water completely solvates the ions already at low concentrations high density clusters of ionic liquid were found even at concentrations as low as $10 \%$. The poor interaction between ions and DMSO thereby showed suggests that DMSO could be used as a rather inert co-solvent, leaving the ionic liquid intact to act as solvent [143].

Recently an interest in so called switchable or distillable ionic liquids has risen. One important reason for this is the need to recycle and also purify the ionic liquid after use. By reintroducing molecular traits of the ionic liquid, i.e. turning it into a molecular solvent (mixture), it may be possible to distill the components and thereby achieve high purities. Thermal instability of the solvent may actually have a profound impact on the choice of recycling techniques. The possibility of irreversible decomposition of the ionic liquid must be taken into account, and there are several routes by which the e.g. the imidazolium cation can decompose [144]. This concept may contradict the often assumed statements that ionic liquids in general are both non-volatile and thermally stable. Imidazolium based ionic liquids are known to decompose under temperatures exceeding $200{ }^{\circ} \mathrm{C}$ and reduced pressure. EMIMCl shows fragmentation into 1-methylimidazole, 1-ethylimidazole, chloromethane and chloroethane [145]. The fragments obtained by thermolysis can be further distilled and separated for later use as starting materials in a reaction to regenerate the original ionic liquid [146]. Problems arise when the thermal decomposition occurs unexpected or via unknown routes. Recent investigations have shown that common ionic liquids such as EMIMCl and $\mathrm{BMIMCl}$ start to degrade already at temperatures around 120 ${ }^{\circ} \mathrm{C}$ [144]. The free acids resulting from the decomposition may cause problems in carbohydrate processing, since depolymerization can be expected.

In 2009, BASF patented a method for distillation of ionic liquids such as the cellulose solvent EMIMAc. For a successful distillation, the ionic liquid must be converted into volatile compounds, which upon condensation again form the wanted salt. The results were good, but not outstanding, with a yield of $>90 \%$ and a purity of $>95 \%$ at $170{ }^{\circ} \mathrm{C}$ [147]. The failure to reach better results is most likely due to side reactions where unwanted decomposition occurs.

Recently, a new class of distillable tetramethylguanidine based ionic liquids was found to dissolve cellulose. In this case, the ionic liquid will dissociate and form the volatile corresponding acid and base pair [29]. Decreased temperature will again form the ionic liquid, according to the equilibrium in Figure 14. In this case, the distillation can be very successful and the reported yield and purity both exceeded $99 \%$. 
<smiles>CN(C)C(=[NH2+])N(C)C</smiles><smiles>CCC(=O)[O-]</smiles>

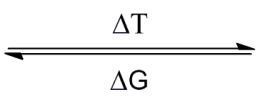<smiles>CN(C)C(=N)N(C)C</smiles><smiles>CCC(=O)O</smiles>

Figure 14. Distillation of a tetramethylguanidine based ionic liquid.

\section{Cellulose solutions}

Due to the strong tendency to self-aggregation in cellulose and the challenge of finding a proper solvent, most industrial cellulose solutions are actually not true molecular solutions. Knowledge of the character of the solution system is of importance for optimization of industrial systems as well as in academia, e.g. for characterization of the polymer using size exclusion chromatography. Comparisons between the cellulose structures in different solvents may be performed using e.g. small angle X-ray scattering (SAXS), small angle light scattering (SLS), dynamic light scattering (DLS) and depolarized dynamic light scattering (DDLS) [148].

Several different models of partially substituted cellulose in solution have been proposed. By light scattering experiments it is possible to approximate the aggregation number, and also the shape of the cellulose aggregates, if present. Models suggest star-branched macromolecules or fringed micelles [149-150]. However, these models were based on experiments using cellulose derivatives and even low degree of substitution may significantly change the behavior of the polymer in a given solvent.

For high concentration cellulose solutions very different behavior can be observed. Lyotropic mesophases or liquid crystalline phases in solutions of $\mathrm{NMMO} /$ cellulose are thought to be possible if the concentration of cellulose exceeds $20 \%$ [151-153]. Comparable solutions can also be formed in an ammonia/ammonium thiocyanate solvent. The nature of the solution can be controlled to selectively produce lyotropic cellulose mesophases having either nematic or cholesteric character. High strength, high modulus fibers can be produced from a solution of cellulose in the nematic phase. Films can be prepared from mesophase solutions of cellulose that are mainly in the cholesteric phase. Material properties vary significant with cellulose concentration [154]. Similar solutions for fiber spinning applications have been prepared and solution anisotropy have been observed using inorganic acids [155] and ionic liquids [121, 133, 156] at cellulose concentrations over $10 \%$. For DMAc/LiCl solutions of cellulose, the polymer concentrations needs to exceed $15 \%$ [98].

The ordered structure can be induced not only in the liquid state but of course also in the gel like state. Nematic ordered films were prepared from molecularly dispersed DMAc/LiCl solutions by stretching of a water swollen gel phase attained by slow coagulation in water vapor [157]. Still, the mechanisms of liquid crystalline phase transition and gel-sol transition are not yet fully understood and much research is left to do. The question must be raised whether to actually define liquid crystalline phases as true solutions when obvious anisotropy is present. 


\section{Conclusions}

The development and optimization of efficient cellulose solvents have had tremendous impact on cellulose processing for well over a hundred years, and will continue to be important as the interest in cellulose itself as a basis for new materials and other applications is increasing. The most important question when considering the dissolution of cellulose is what the purpose of keeping the cellulose in solution will be. For homogeneous reactions in small scale the requirements on the solvents may be completely different from those in a large scale industrial facility for dissolution and shaping of cellulose where the purpose of regeneration is not only to stabilize the physical structure but also regain the original chemical composition of the polymer. Degree of polymerization, source and purity of the cellulose as well as required concentration in the solution may also have a profound effect on the choice of solvent.

A wide variety of suitable solvents for cellulose are already available, both aqueous and non-aqueous. Despite this, feverish activity goes on in both industry and academia to optimize existing solvent systems and develop new ones. Ideally, such a new cellulose solvent would of course be efficient and inert towards the polymer itself. It would also be $100 \%$ recyclable and non-hazardous to environment and man. To meet future requirements on "green chemistry" and sustainability, it would be produced from non-hazardous starting materials and upon final degradation give non-hazardous, biodegradable products only. Proper life cycle assessment could be conducted to see if any new solvent meets these demands.

New materials produced from cellulose raw material are claimed to fall under the category of sustainable development because the cellulose is a polymer that replenishes itself in plants by air, water and solar energy. However, the chemistry we apply to modify and shape the cellulose to whatever form we desire must also be considered. Solvents are no exception, especially not since they are often used in great excess meaning large quantities. Truly sustainable polymer based materials are only achieved by using a sustainable polymer in combination with a sustainable chemistry to finalize the product. The quest for the cellulose solvent of the future goes on.

\section{Author details}

\section{Carina Olsson}

Corresponding Author

Department of Chemical and Biological Engineering, Chalmers University of Technology, Gothenburg, Sweden

Gunnar Westman

Department of Chemical and Biological Engineering, Chalmers University of Technology, Gothenburg, Sweden 


\section{Acknowledgement}

The authors would like to acknowledge Prof. Herbert Sixta and Dr. Merima Hasani for valuable discussions and critical reading of the manuscript. Many thanks also to Södra Cell for financial support.

\section{References}

[1] Cross, C.F., Bevan, E.T. and Beadle, C. (1893). Thiokohlensäureester der Cellulose. Berichte der deutschen chemischen Gesellschaft, 26(1): 1090-1097.

[2] Loth, F., Schaaf, E., Fink, H.P., Kunze, J. and Gensrich, H.J. Verfahren zur Herstellung von Cellulosecarbamat in Einem Inerten Organischen, mit Wasser Nicht Mischbaren Lösungsmittel. Germany patent (2004).

[3] Rentto, M.E. (2011). Avilon Develops Environmental Friendly Cleantch Innovation. Available: $\quad$ http://www.cisionwire.com/neo-industrial-plc-g/r/avilon-developsenvironmental-friendly-cleantech-innovation,e200454. Accessed 2012 April 13.

[4] Manjkow, J., Papanu, J.S., Hess, D.W., Soane, D.S. and Bell, A.T. (1987). Influence of Processing and Molecular Parameters in the Dissolution Rate of Poly-(Methyl Methacrylate Thin Films. Journal of the Electrochemical Society, 134(8): 2003-2007.

[5] Miller-Chou, B.A. and Koenig, J.L. (2003). A Review of Polymer Dissolution. Progress in Polymer Science, 28(8): 1223-1270.

[6] Bovey, F.A. and Winslow, F.H. (1979). Macromolecules. An Introduction to Polymer Science. (New York: Academic press, inc.).

[7] Zugenmaier, P. (2008). History of Cellulose Research. In: Crystalline Cellulose and Cellulose Derivatives. Berlin: Springer Verlag. pp. 7-51.

[8] Chu, S.S.C. and Jeffrey, G. (1968). The Refinement of the Crystal Structures of $\beta$-Dglucose and Cellobiose. Acta Crystallographica, 24: 830-838.

[9] Ferrier, W.G. (1963). The Crystal and Molecular Structure of $\beta$-D-glucose. Acta Crystallographica, 16: 1023-1031.

[10] Nehls, I., Wagenknecht, W., Philipp, B. and Stscherbina, D. (1994). Characterization of Cellulose and Cellulose Derivatives in Solution by High Resolution ${ }^{13} \mathrm{C}-\mathrm{NMR}$ Spectroscopy. Progress in Polymer Science, 19(1): 29-78.

[11] Nishiyama, Y., Langan, P. and Chanzy, H. (2002). Crystal Structure and HydrogenBonding System in Cellulose I $\beta$ from Synchrotron $X$-ray and Neutron Fiber Diffraction. Journal of the American Chemical Society, 124(31): 9074-9082.

[12] Goring, D.A.I. and Timell, T.E. (1962). Molecular Weight of Native Celluloses. Tappi, 45(6): 454-460.

[13] Nishikawa, S. and Ono, S. (1913). Transmission of X-rays Through Fibrous, Lamellar and Granular Substances. Proceedings of the Tokyo Mathematico-Physical Society, 7: 131-138. 
[14] Gardner, K.H. and Blackwell, J. (1974). The Structure of Native Cellulose. Biopolymers, 13(10): 1975-2001.

[15] Atalla, R.H. and VanderHart, D.L. (1984). Native Cellulose: A Composite of Two Distinct Crystalline Forms. Science, 223(4633): 283-285.

[16] VanderHart, D.L. and Atalla, R.H. (1984). Studies of Microstructure in Native Celluloses Using Solid-State Carbon-13 NMR. Macromolecules, 17(8): 1465-1472.

[17] Finkenstadt, V.L. and Millane, R.P. (1998). Crystal Structure of Valonia Cellulose I $\beta$. Macromolecules, 31(22): 7776-7783.

[18] Langan, P., Nishiyama, Y. and Chanzy, H. (2001). X-ray Structure of Mercerized Cellulose II at $1 \AA$ A Resolution. Biomacromolecules, 2(2): 410-416.

[19] Kolpak, F.J. and Blackwell, J. (1978). Mercerization of Cellulose: 2. The Morphology of Mercerized Cotton Cellulose. Polymer, 19(2): 132-135.

[20] Lejeune, A. and Deprez, T. (2010). Cellulose: Structure and Properties, Derivatives and Industrial Uses

[21] Revol, J.F. (1982). On the Cross-Sectional Shape of Cellulose Crystallites in Valonia ventricosa. Carbohydrate Polymers, 2(2): 123-134.

[22] Frey-Wyssling, A. and Muehlenthaler, K. (1963). The Elementary Fibrils of Cellulose. Makromolekulare Chemie, 62: 25-30.

[23] Hearle, J.W.S. (1958). A Fringed Fibril Theory of Structure in Crystalline Polymers. Journal of Polymer Science, 28(117): 432-435.

[24] Fink, H.P., Hofmann, D. and Philipp, B. (1995). Some Aspects of Lateral Chain Order in Cellulosics from X-ray Scattering. Cellulose, 2(1): 51-70.

[25] Reichardt, C. (1994). Solvatochromic Dyes as Solvent Polarity Indicators. Chemical Reviews, 94(8): 2319-2358.

[26] Spange, S., Reuter, A., Vilsmeier, E., Heinze, T., Keutel, D. and Linert, W. (1998). Determination of Empirical Polarity Parameters of the Cellulose Solvent N,NDimethylacetamide/LiCl by Means of the Solvatochromic Technique. Journal of Polymer Science Part A: Polymer Chemistry, 36(11): 1945-1955.

[27] Ohno, H. and Fukumoto, K. (2007). Amino Acid Ionic Liquids. Accounts of Chemical Research, 40(11): 1122-1129.

[28] Fukaya, Y., Iizuka, Y., Sekikawa, K. and Ohno, H. (2007). Bio Ionic Liquids: Room Temperature Ionic Liquids Composed Wholly of Biomaterials. Green Chemistry, 9(11): 1155-1157.

[29] King, A.W.T., Asikkala, J., Mutikainen, I., Järvi, P. and Kilpeläinen, I. (2011). Distillable Acid-Base Conjugate Ionic Liquids for Cellulose Dissolution and Processing. Angewandte Chemie International Edition, 50(28): 6301-6305.

[30] Taft, R.W., Abboud, J.-L.M., Kamlet, M.J. and Abraham, M.H. (1985). Linear Solvation Energy Relations. Journal of Solution Chemistry, 14(3): 153-186.

[31] Marcus, Y. (1993). The Properties of Organic Liquids that are Relevant to Their Use as Solvating Solvents. Chemical Society Reviews, 22(6): 409-416. 
[32] Lindman, B., Karlström, G. and Stigsson, L. (2010). On the Mechanism of Dissolution of Cellulose. Journal of Molecular Liquids, 156(1): 76-81.

[33] Lindman, B. (2010). Amphiphilic Biopolymers. In: M. Fanun (Ed.), Colloids in Biotechnology. CRC Press. pp. 1-7.

[34] Biermann, O., Hädicke, E., Koltzenburg, S. and Müller-Plathe, F. (2001). Hydrophilicity and Lipophilicity of Cellulose Crystal Surfaces. Angewandte Chemie International Edition, 40(20): 3822-3825.

[35] Bergenstråhle, M., Mazeau, K. and Berglund, L.A. (2008). Molecular Modeling of Interfaces Between Cellulose Crystals and Surrounding Molecules: Effects of Caprolactone Surface Grafting. European Polymer Journal, 44(11): 3662-3669.

[36] Cho, H.M., Gross, A.S. and Chu, J.-W. (2011). Dissecting Force Interactions in Cellulose Deconstruction Reveals the Required Solvent Versatility for Overcoming Biomass Recalcitrance. Journal of the American Chemical Society, 133(35): 14033-14041.

[37] Gross, A.S. and Chu, J.-W. (2010). On the Molecular Origins of Biomass Recalcitrance: The Interaction Network and Solvation Structures of Cellulose Microfibrils. The Journal of Physical Chemistry B, 114(42): 13333-13341.

[38] Beckham, G.T., Matthews, J.F., Peters, B., Bomble, Y.J., Himmel, M.E. and Crowley, M.F. (2011). Molecular-Level Origins of Biomass Recalcitrance: Decrystallization Free Energies for Four Common Cellulose Polymorphs. The Journal of Physical Chemistry B, 115(14): 4118-4127.

[39] Betzel, C., Saenger, W., Hingerty, B.E. and Brown, G.M. (1984). Topography of Cyclodextrin Inclusion Complexes, Part 20. Circular and Flip-Flop Hydrogen Bonding in Beta-Cyclodextrin Undecahydrate: a Neutron Diffraction Study. Journal of the American Chemical Society, 106(24): 7545-7557.

[40] Griffiths, D.W. and Bender, M.L. (1973). Cycloamyloses as Catalysts. Advances in Catalysis, 23: 209-61.

[41] Clarke, R.J., Coates, J.H. and Lincoln, S.F. (1988). Inclusion Complexes of the Cyclomalto-Oligosaccharides (Cyclodextrins). In: R. S. Tipson and H. Derek (Eds.), Advances in Carbohydrate Chemistry and Biochemistry. Academic Press. pp. 205-249.

[42] Sasaki, M., Fang, Z., Fukushima, Y., Adschiri, T. and Arai, K. (2000). Dissolution and Hydrolysis of Cellulose in Subcritical and Supercritical Water. Industrial \& Engineering Chemistry Research, 39(8): 2883-2890.

[43] Sasaki, M., Adschiri, T. and Arai, K. (2004). Kinetics of Cellulose Conversion at $25 \mathrm{MPa}$ in Sub- and Supercritical Water. AIChE Journal, 50(1): 192-202.

[44] Yu, Y. and Wu, H. (2009). Characteristics and Precipitation of Glucose Oligomers in the Fresh Liquid Products Obtained from the Hydrolysis of Cellulose in Hot-Compressed Water. Industrial \& Engineering Chemistry Research, 48(23): 10682-10690.

[45] Kamide, K., Okajima, K., Matsui, T. and Kowsaka, K. (1984). Study on the Solubility of Cellulose in Aqueous Alkali Solution by Deuteration IR and ${ }^{13} \mathrm{C}$ NMR. Polymer Journal, 16(12): 857-866. 
[46] Isogai, A. and Atalla, R.H. (1998). Dissolution of Cellulose in Aqueous NaOH Solutions. Cellulose, 5(4): 309-319.

[47] Isogai, A., Chiba, J., Atalla, R.H. and Verona, W. Alkaline Method for Dissolving Cellulose (1994).

[48] Sobue, H., Kiessig, H. and Hess, K. (1939). The System: Cellulose-Sodium HydroxideWater in Relation to the Temperature. Zeitschrift für Physikalishe Chemie, B43: 309.

[49] Roy, C., Budtova, T. and Navard, P. (2003). Rheological Properties and Gelation of Aqueous Cellulose-NaOH Solutions. Biomacromolecules, 4(2): 259-264.

[50] Yan, L. and Gao, Z. (2008). Dissolving of Cellulose in PEG/NaOH Aqueous Solution. Cellulose, 15(6): 789-796.

[51] Han, D. and Yan, L. (2010). Preparation of All-Cellulose Composite by Selective Dissolving of Cellulose Surface in $\mathrm{PEG} / \mathrm{NaOH}$ Aqueous Solution. Carbohydrate Polymers, 79(3): 614-619.

[52] Zhang, L., Ruan, D. and Zhou, J. (2001). Structure and Properties of Regenerated Cellulose Films Prepared from Cotton Linters in NaOH/Urea Aqueous Solution. Industrial \& Engineering Chemistry Research, 40(25): 5923-5928.

[53] Zhang, L., Ruan, D. and Gao, S. (2002). Dissolution and Regeneration of Cellulose in $\mathrm{NaOH}$ /Thiourea Aqueous Solution. Journal of Polymer Science Part B: Polymer Physics, 40(14): 1521-1529.

[54] Jin, H., Zha, C. and Gu, L. (2007). Direct Dissolution of Cellulose in $\mathrm{NaOH} /$ Thiourea/Urea Aqueous Solution. Carbohydrate Research, 342(6): 851-858.

[55] Zhang, S., Li, F.-X., Yu, J.-y. and Hsieh, Y.-L. (2010). Dissolution Behaviour and Solubility of Cellulose in NaOH Complex Solution. Carbohydrate Polymers, 81(3): 668674.

[56] Trygg, J. and Fardim, P. (2011). Enhancement of Cellulose Dissolution in Water-Based Solvent via Ethanol-Hydrochloric Acid Pretreatment. Cellulose, 18(4): 987-994.

[57] Egal, M., Budtova, T. and Navard, P. (2008). The Dissolution of Microcrystalline Cellulose in Sodium Hydroxide-Urea Aqueous Solutions. Cellulose, 15(3): 361-370.

[58] Cai, J., Zhang, L., Liu, S., Liu, Y., Xu, X., Chen, X., Chu, B., Guo, X., Xu, J., Cheng, H., Han, C.C. and Kuga, S. (2008). Dynamic Self-Assembly Induced Rapid Dissolution of Cellulose at Low Temperatures. Macromolecules, 41(23): 9345-9351.

[59] Qi, H., Yang, Q., Zhang, L., Liebert, T. and Heinze, T. (2011). The Dissolution of Cellulose in NaOH-based Aqueous System by Two-Step Process. Cellulose, 18(2): 237245.

[60] Yang, Q., Fukuzumi, H., Saito, T., Isogai, A. and Zhang, L. (2011). Transparent Cellulose Films with High Gas Barrier Properties Fabricated from Aqueous Alkali/Urea Solutions. Biomacromolecules, 12(7): 2766-2771.

[61] Chen, X., Burger, C., Wan, F., Zhang, J., Rong, L., Hsiao, B.S., Chu, B., Cai, J. and Zhang, L. (2007). Structure Study of Cellulose Fibers Wet-Spun from Environmentally Friendly $\mathrm{NaOH} /$ Urea Aqueous Solutions. Biomacromolecules, 8(6): 1918-1926. 
[62] Ruan, D., Zhang, L., Zhou, J., Jin, H. and Chen, H. (2004). Structure and Properties of Novel Fibers Spun from Cellulose in $\mathrm{NaOH} /$ Thiourea Aqueous Solution. Macromolecular Bioscience, 4(12): 1105-1112.

[63] Chen, X., Burger, C., Fang, D., Ruan, D., Zhang, L., Hsiao, B.S. and Chu, B. (2006). X-ray Studies of Regenerated Cellulose Fibers Wet Spun From Cotton Linter Pulp in $\mathrm{NaOH} /$ Thiourea Aqueous Solutions. Polymer, 47(8): 2839-2848.

[64] Cai, J. and Zhang, L. (2005). Rapid Dissolution of Cellulose in LiOH/Urea and $\mathrm{NaOH} /$ Urea Aqueous Solutions. Macromolecular Bioscience, 5(6): 539-548.

[65] Qi, H., Liebert, T., Meister, F., Zhang, L. and Heinze, T. (2010). Homogenous Carboxymethylation of Cellulose in the New Alkaline Solvent LiOH/Urea Aqueous Solution. Macromolecular Symposia, 294(2): 125-132.

[66] Zhou, J., Qin, Y., Liu, S. and Zhang, L. (2006). Homogenous Synthesis of Hydroxyethylcellulose in $\mathrm{NaOH} / \mathrm{Urea}$ Aqueous Solution. Macromolecular Bioscience, 6(1): 84-89.

[67] Heinze, T. and Liebert, T. (2001). Unconventional methods in cellulose functionalization. Progress in Polymer Science, 26(9): 1689-1762.

[68] Saalwächter, K., Burchard, W., Klüfers, P., Kettenbach, G., Mayer, P., Klemm, D. and Dugarmaa, S. (2000). Cellulose Solutions in Water Containing Metal Complexes. Macromolecules, 33(11): 4094-4107.

[69] Ahlrichs, R., Ballauff, M., Eichkorn, K., Hanemann, O., Kettenbach, G. and Klüfers, P. (1998). Aqueous Ethylenediamine Dihydroxo Palladium(II): A Coordinating Agent for Low- and High-Molecular Weight Carbohydrates. Chemistry - A European Journal, 4(5): 835-844.

[70] Hanemann, O. and Ballauff, M. (1997). Chain Conformation of Cellulose in a Coordinating Solvent. Macromolecules, 30(24): 7638-7640.

[71] Woodings, C. (2001). Regenerated Cellulose Fibres. Cambridge: Woodhead publishing Ltd.

[72] Heinze, T., Liebert, T., Klüfers, P. and Meister, F. (1999). Carboxymethylation of Cellulose in Unconventional Media. Cellulose, 6(2): 153-165.

[73] Sjöström, E. (1993). Wood Chemistry: Fundamentals and Applications (2nd ed.). San Diego: Academic press.

[74] Fischer, S., Leipner, H., Thümmler, K., Brendler, E. and Peters, J. (2003). Inorganic Molten Salts as Solvents for Cellulose. Cellulose, 10(3): 227-236.

[75] Fischer, S. and Thümmler, K. (2010). Molten Inorganic Salts as Reaction Medium for Cellulose. In: Cellulose Solvents: For Analysis, Shaping and Chemical Modification. American Chemical Society. pp. 91-101.

[76] Hattori, M., Koga, T., Shimaya, Y. and Saito, M. (1998). Aqueous Calcium Thiocyanate Solution as a Cellulose Solvent. Structure and Interactions with Cellulose. Polymer Journal, 30(1): 43-48.

[77] Hattori, M., Shimaya, Y. and Saito, M. (1998). Structural Changes in Wood Pulp Treated by $55 \mathrm{wt} \%$ Aqueous Calcium Thiocyanate Solution. Polymer Journal, 30(1): 37-42. 
[78] Brendler, E., Fischer, S. and Leipner, H. (2001). ${ }^{7}$ Li NMR as Probe for Solvent-Cellulose Interactions in Cellulose Dissolution. Cellulose, 8(4): 283-288.

[79] Leipner, H., Fischer, S., Brendler, E. and Voigt, W. (2000). Structural Changes of Cellulose Dissolved in Molten Salt Hydrates. Macromolecular Chemistry and Physics, 201(15): 2041-2049.

[80] Fischer, S., Thümmler, K., Pfeiffer, K., Liebert, T. and Heinze, T. (2002). Evaluation of Molten Inorganic Salt Hydrates as Reaction Medium for the Derivatization of Cellulose. Cellulose, 9(3): 293-300.

[81] Thümmler, K., Fischer, S., Peters, J., Liebert, T. and Heinze, T. (2010). Evaluation of Molten Inorganic Salt Hydrates as Reaction Medium for the Esterification of Cellulose. Cellulose, 17(1): 161-165.

[82] Battista, O.A. (1950). Hydrolysis and Crystallization of Cellulose. Industrial \& Engineering Chemistry, 42(3): 502-507.

[83] Battista, O.A., Coppick, S., Howsmon, J.A., Morehead, F.F. and Sisson, W.A. (1956). Level-Off Degree of Polymerization - Relation to Polyphase Structure of Cellulose Fibers. Industrial and engineering chemistry, 48(2): 333-335.

[84] Liebert, T., Seifert, M. and Heinze, T. (2008). Efficient Method for the Preparation of Pure, Water-Soluble Cellodextrines. Macromolecular Symposia, 262(1): 140-149.

[85] Akpinar, O., McGorrin, R.J. and Penner, M.H. (2004). Cellulose-Based Chromatography for Cellooligosaccharide Production. Journal of Agricultural and Food Chemistry, 52(13): 4144-4148.

[86] Miller, G.L., Dean, J. and Blum, R. (1960). A Study of Methods for Preparing Oligosaccharides from Cellulose. Archives of Biochemistry and Biophysics, 91(1): 21-26.

[87] Zhang, Y.-H.P. and Lynd, L.R. (2003). Cellodextrin Preparation by Mixed-Acid Hydrolysis and Chromatographic Separation. Analytical Biochemistry, 322(2): 225-232.

[88] Celanese, B. Improvements in Phosphoric Acid Solutions of Cellulose. GB patent GB 263810 (A) (1927).

[89] Zhang, Y.H.P., Cui, J., Lynd, L.R. and Kuang, L.R. (2006). A Transition from Cellulose Swelling to Cellulose Dissolution by o-Phosphoric Acid: Evidence from Enzymatic Hydrolysis and Supramolecular Structure. Biomacromolecules, 7(2): 644-648.

[90] Boerstoel, H., Maatman, H., Westerink, J.B. and Koenders, B.M. (2001). Liquid Crystalline Solutions of Cellulose in Phosphoric Acid. Polymer, 42(17): 7371-7379.

[91] Northolt, M.G., Boerstoel, H., Maatman, H., Huisman, R., Veurink, J. and Elzerman, H. (2001). The Structure and Properties of Cellulose Fibres Spun From an Anisotropic Phosphoric Acid Solution. Polymer, 42(19): 8249-8264.

[92] Heinze, T. and Koschella, A. (2005). Solvents Applied in the Field of Cellulose Chemistry: a Mini Review. Polímeros, 15: 84-90.

[93] Graenacher, C. Cellulose Solution. U.S. Patent 1,943,176 (1934).

[94] Striegel, A. (1997). Theory and Applications of $\mathrm{DMAC} / \mathrm{LiCl}$ in the Analysis of Polysaccharides. Carbohydrate Polymers, 34(4): 267-274. 
[95] Austin, P.R., Brine, C.J., Castle, J.E. and Zikakis, J.P. (1981). Chitin: New Facets of Research. Science, 212(4496): 749-753.

[96] McCormick, C.L. and Callais, P.A. (1987). Derivatization of Cellulose in Lithium Chloride and N-N-Dimethylacetamide Solutions. Polymer, 28(13): 2317-2323.

[97] McCormick, C.L. Novel Cellulose Solutions. (1981).

[98] McCormick, C.L., Callais, P.A. and Hutchinson, B.H. (1985). Solution Studies of Cellulose in Lithium Chloride and N,N-Dimethylacetamide. Macromolecules, 18(12): 2394-2401.

[99] Potthast, A., Rosenau, T., Buchner, R., Röder, T., Ebner, G., Bruglachner, H., Sixta, H. and Kosma, P. (2002). The Cellulose Solvent System N,N-Dimethylacetamide/Lithium Chloride Revisited: the Effect of Water on Physicochemical Properties and Chemical Stability. Cellulose, 9(1): 41-53.

[100] Oliveira, W.D. and Glasser, W.G. (1996). Hydrogels from Polysaccharides. I. Cellulose Beads for Chromatographic Support. Journal of Applied Polymer Science, 60(1): 63-73.

[101] El Seoud, O.A., Marson, G.A., Ciacco, G.T. and Frollini, E. (2000). An Efficient, One-Pot Acylation of Cellulose under Homogeneous Reaction Conditions. Macromolecular Chemistry and Physics, 201(8): 882-889.

[102] Tosh, B., Saikia, C.N. and Dass, N.N. (2000). Homogeneous Esterification of Cellulose in the Lithium Chloride-N,N-Dimethylacetamide Solvent System: Effect of Temperature and Catalyst. Carbohydrate Research, 327(3): 345-352.

[103] Bikova, T. and Treimanis, A. (2002). Problems of the MMD Analysis of Cellulose by SEC using DMA/LiCl: A Review. Carbohydrate Polymers, 48(1): 23-28.

[104] Potthast, A., Rosenau, T., Sixta, H. and Kosma, P. (2002). Degradation of Cellulosic Materials by Heating in DMAc/LiCl. Tetrahedron Letters, 43(43): 7757-7759.

[105] Heinze, T. and Köhler, S. (2010). Dimethyl Sulfoxide and Ammonium Fluorides Novel Cellulose Solvents. In: Cellulose Solvents: For Analysis, Shaping and Chemical Modification. American Chemical Society. pp. 103-118.

[106] Heinze, T., Dicke, R., Koschella, A., Kull, A.H., Klohr, E.-A. and Koch, W. (2000). Effective Preparation of Cellulose Derivatives in a New Simple Cellulose Solvent. Macromolecular Chemistry and Physics, 201(6): 627-631.

[107] Östlund, Å., Lundberg, D., Nordstierna, L., Holmberg, K. and Nydén, M. (2009). Dissolution and Gelation of Cellulose in TBAF/DMSO Solutions: The Roles of Fluoride Ions and Water. Biomacromolecules, 10(9): 2401-2407.

[108] Chen, Y., Stipanovic, A., Winter, W., Wilson, D. and Kim, Y.-J. (2007). Effect of Digestion by Pure Cellulases on Crystallinity and Average Chain Length for Bacterial and Microcrystalline Celluloses. Cellulose, 14(4): 283-293.

[109] Ass, B.A.P., Frollini, E. and Heinze, T. (2004). Studies on the Homogeneous Acetylation of Cellulose in the Novel Solvent Dimethyl Sulfoxide/Tetrabutylammonium Fluoride Trihydrate. Macromolecular Bioscience, 4(11): 1008-1013.

[110] Hussain, M.A., Liebert, T. and Heinze, T. (2004). Acylation of Cellulose with N,N'Carbonyldiimidazole-Activated Acids in the Novel Solvent Dimethyl 
Sulfoxide/Tetrabutylammonium Fluoride. Macromolecular Rapid Communications, 25(9): 916-920.

[111] Sharma, R.K. and Fry, J.L. (1983). Instability of Anhydrous Tetra-NormalAlkylammonium Fluorides. Journal of Organic Chemistry, 48(12): 2112-2114.

[112] Köhler, S. and Heinze, T. (2007). New Solvents for Cellulose: Dimethyl Sulfoxide/Ammonium Fluorides. Macromolecular Bioscience, 7(3): 307-314.

[113] Maia, E., Peguy, A. and Perez, S. (1981). Cellulose Organic Solvents. I. The Structures of Anhydrous N-Methylmorpholine N-Oxide and N-Methylmorpholine N-Oxide Monohydrate. Acta Crystallographica Section B, 37(10): 1858-1862.

[114] Rosenau, T., Potthast, A., Sixta, H. and Kosma, P. (2001). The Chemistry of Side Reactions and Byproduct Formation in the System NMMO/Cellulose (Lyocell process). Progress in Polymer Science, 26(9): 1763-1837.

[115] Rosenau, T., Potthast, A., Hofinger, A., Sixta, H. and Kosma, P. (2002). Instabilities in the System NMMO/Water/Cellulose (Lyocell Process) Caused by Polonowski Type Reactions. Holzforschung, 56(2): 199-208.

[116] Adorjan, I., Potthast, A., Rosenau, T., Sixta, H. and Kosma, P. (2005). Discoloration of Cellulose Solutions in N-Methylmorpholine-N-Oxide (Lyocell). Part 1: Studies on Model Compounds and Pulps. Cellulose, 12(1): 51-57.

[117] Rosenau, T., Potthast, A., Adorjan, I., Hofinger, A., Sixta, H., Firgo, H. and Kosma, P. (2002). Cellulose Solutions in N-Methylmorpholine-N-Oxide (NMMO) - Degradation Processes and Stabilizers. Cellulose, 9(3): 283-291.

[118] Klemm, D., Heublein, B., Fink, H.-P. and Bohn, A. (2005). Cellulose: Fascinating Biopolymer and Sustainable Raw Material. Angewandte Chemie International Edition, 44(22): 3358-3393.

[119] Maron, R., Michels, C. and Taeger, E. (1994). Investigations for Preparation of Cellulose Solutions in NMMO and the Following Forming. Lenzinger Berichte, 9: 27-29.

[120] Röder, T. and Morgenstern, B. (1999). The Influence of Activation on the Solution State of Cellulose Dissolved in N-Methylmorpholine-N-Oxide-Monohydrate. Polymer, 40(14): 4143-4147.

[121] Swatloski, R.P., Spear, S.K., Holbrey, J.D. and Rogers, R.D. (2002). Dissolution of Cellose with Ionic Liquids. Journal of the American Chemical Society, 124(18): 49744975.

[122] Viswanathan, G., Murugesan, S., Pushpraj, V., Nalamasu, O., Ajayan, P.M. and Linhardt, R.J. (2006). Preparation of Biopolymer Fibers by Electrospinning from Room Temperature Ionic Liquids. Biomacromolecules, 7(2): 415-418.

[123] Kosan, B., Michels, C. and Meister, F. (2008). Dissolution and Forming of Cellulose with Ionic Liquids. Cellulose, 15: 59-66.

[124] Heinze, T., Schwikal, K. and Barthel, S. (2005). Ionic Liquids as Reaction Medium in Cellulose Functionalization. Macromolecular Bioscience, 5: 520-525. 
[125] Sun, N., Rahman, M., Qin, Y., Maxim, M.L., Rodriguez, H. and Rogers, R.D. (2009). Complete Dissolution and Partial Delignification of Wood in the Ionic Liquid 1-ethyl-3Methylimidazolium Acetate. Green Chemistry, 11(5): 646-655.

[126] Ilkka Kilpeläinen, H.X., Alistair King, Mari Granstrom, Sami Heikkinen, Dimitris S. Argyropoulus. (2007). Dissolution of Wood in Ionic Liquids. Agricultural and Food Chemistry, 55(22): 9142-9148.

[127] Fort, D.A., Remsing, R.C., Swatloski, R.P., Moyna, P. and Rogers, G.M.R.D. (2007). Can Ionic Liquids Dissolve Wood? Processing and Analysis of Lignocellulosic Materials with 1-N-Butyl-3-Methylimidazolium Chloride. Green Chemistry, 9: 63-69.

[128] Swatloski, R.P., Spear, S.K., Holbrey, J.D. and Rogers, R.D. (2002). Dissolution of Cellulose with Ionic Liquids. Journal of the American Chemical Society, 124(18): 49744975.

[129] Vitz, J., Erdmenger, T., Haensch, C. and Schubert, U.S. (2009). Extended Dissolution Studies of Cellulose in Imidazolium Based ionic Liquids. Green Chemistry, 11(3): 417424.

[130] Zheng, W., Mohammed, A., Hines, L.G., Xiao, D., Martinez, O.J., Bartsch, R.A., Simon, S.L., Russina, O., Triolo, A. and Quitevis, E.L. (2011). Effect of Cation Symmetry on the Morphology and Physicochemical Properties of Imidazolium Ionic Liquids. The Journal of Physical Chemistry B, 115(20): 6572-6584.

[131] Remsing, R.C., Swatloski, R.P., Rogers, R.D. and Moyna, G. (2006). Mechanism of Cellulose Dissolution in the Ionic Liquid 1-N-Butyl-3-Methylimidazolium Chloride: a ${ }^{13} \mathrm{C}$ and ${ }^{35 / 37} \mathrm{Cl}$ NMR Relaxation Study on Model systems. Chemical Communications (12): 1271-1273.

[132] Zhang, J., Zhang, H., Wu, J., Zhang, J., He, J. and Xiang, J. (2010). NMR Spectroscopic Studies of Cellobiose Solvation in EmimAc Aimed to Understand the Dissolution Mechanism of Cellulose in Ionic Liquids. Physical Chemistry Chemical Physics, 12(8): 1941-1947.

[133] Zhang, H., Wu, J., Zhang, J. and He, J. (2005). 1-Allyl-3-Methylimidazolium Chloride Room Temperature Ionic Liquid: A New and Powerful Nonderivatizing Solvent for Cellulose. Macromolecules, 38(20): 8272-8277.

[134] Feng, L. and Chen, Z.-1. (2008). Research Progress on Dissolution and Functional Modification of Cellulose in Ionic Liquids. Journal of Molecular Liquids, 142(1-3): 1-5.

[135] Gericke, M., Schlufter, K., Liebert, T., Heinze, T. and Budtova, T. (2009). Rheological Properties of Cellulose/Ionic Liquid Solutions: From Dilute to Concentrated States. Biomacromolecules, 10(5): 1188-1194.

[136] Wu, J., Zhang, J., Zhang, H., He, J., Ren, Q. and Guo, M. (2004). Homogeneous Acetylation of Cellulose in a New Ionic Liquid. Biomacromolecules, 5(2): 266-268.

[137] Granström, M., Kavakka, J., King, A., Majoinen, J., Mäkelä, V., Helaja, J., Hietala, S., Virtanen, T., Maunu, S.-L., Argyropoulos, D.S. and Kilpeläinen, I. (2008). Tosylation and Acylation of Cellulose in 1-Allyl-3-Methylimidazolium Chloride. Cellulose, 15: 481-488. 
[138] Cao, Y., JinWub, Zhangb, J., Li, H., Zhanga, Y. and Heb, J. (2009). Room Temperature Ionic Liquids (RTILs): A New and Versatile Platform for Cellulose Processing and Derivatization. Chemical Enginering Journal, 147: 13-21.

[139] Mormann, W. and Wezstein, M. (2009). Trimethylsilylation of Cellulose in Ionic Liquids. Macromolecular Bioscience, 9: 369-375.

[140] Köhler, S., Liebert, T., Schöbitz, M., Schaller, J., Meister, F., Günther, W. and Heinze, T. (2007). Interactions of Ionic Liquids with Polysaccharides 1. Unexpected Acetylation of Cellulose with 1-Ethyl-3-methylimidazolium Acetate. Macromolecular Rapid Communications, 28: 2311-2317.

[141] Ebner, G., Schiehser, S., Potthast, A. and Rosenau, T. (2008). Side Reaction of Cellulose with Common 1-alkyl-3-methylimidazolium-based Ionic Liquids. Tetrahedron Letters, 49(51): 7322-7324.

[142] Rinaldi, R. (2011). Instantaneous Dissolution of Cellulose in Organic Electrolyte Solutions. Chemical Communications, 47(1): 511-513.

[143] Remsing, R.C., Liu, Z., Sergeyev, I. and Moyna, G. (2008). Solvation and Aggregation of N,N'-Dialkylimidazolium Ionic Liquids: A Multinuclear NMR Spectroscopy and Molecular Dynamics Simulation Study. The Journal of Physical Chemistry B, 112(25): 7363-7369.

[144] Meine, N., Benedito, F. and Rinaldi, R. (2010). Thermal Stability of Ionic Liquids Assessed by Potentiometric Titration. Green Chemistry, 12(10): 1711-1714.

[145] Jeapes, A.J., Thied, R.C., Seddon, K.R., Pitner, W.R., Rooney, D.W., Hatter, J.E. and Welton, T. Process for Recycling Ionic Liquids. GB patent (2002).

[146] Earle, M.J., Esperanca, J.M.S.S., Gilea, M.A., Canongia Lopes, J.N., Rebelo, L.P.N., Magee, J.W., Seddon, K.R. and Widegren, J.A. (2006). The Distillation and Volatility of Ionic Liquids. Nature, 439(7078): 831-834.

[147] Massone, K., Siemer, M., Mormann, W. and Leng, W. Distillation of Ionic Liquids. Germany patent (2010).

[148] Röder, T., Möslinger, R., Mais, U., Morgenstern, B. and Glatter, O. (2003). Charakterisierung der Lösungsstrukturen in technishen relevanten Celluloselösungen. Lenzinger Berichte, 82: 118-127.

[149] Schmidt, J., Weigel, R., Burchard, W. and Richtering, W. (1997). MethylHydroxypropyl Cellulose - Shear Induced birefringence Measurements in the SemiDilute Regime. Macromolecular Symposia, 120(1): 247-257.

[150] Schulz, L., Seger, B. and Burchard, W. (2000). Structures of Cellulose in Solution. Macromolecular Chemistry and Physics, 201(15): 2008-2022.

[151] Gilbert, R.D. (1994). Cellulosic Polymers, Blends, and Composites: Hanser Publishers.

[152] Michels, C. and Kosan, B. (2003). Contribution to Dissolution State of Cellulose in Aqueous Amine Oxide Charachterized by Optical and Rheological Methods. Lenzinger Berichte, 82: 128-135. 
[153] Kim, S.O., Shin, W.J., Cho, H., Kim, B.C. and Chung, I.J. (1999). Rheological Investigation on the Anisotropic Phase of Cellulose-MMNO/ $\mathrm{H}_{2} \mathrm{O}$ Solution System. Polymer, 40(23): 6443-6450.

[154] Cuculo, e.a. Anisotropic Cellulose Solutions, Fibers, and Films Formed Therefrom. Unites States of America patent (1988).

[155] Boerstoel, H.N.K.B., M.; Westerink, J.B. Cellulose Solutions and Products Made Therefrom. (1996).

[156] Song, H., Niu, Y., Wang, Z. and Zhang, J. (2011). Liquid Crystalline Phase and Gel-Sol Transitions for Concentrated Microcrystalline Cellulose (MCC)/1-Ethyl-3Methylimidazolium Acetate (EMIMAc) Solutions. Biomacromolecules, 12(4): 1087-1096.

[157] Tetsuo Kondo, E.T., and R. Malcolm Br. (2001). "Nematic Ordered Cellulose": A Concept of Glucan Chain Association. Biomcaromolecules, 2(4): 1324-1330. 